University of Windsor

Scholarship at UWindsor

2016

\title{
Short-term fasts increase levels of halogenated flame retardants in tissues of a wild incubating bird
}

S. C. Marteinson

K. G. Drouillard

University of Windsor

J. Verreault

Follow this and additional works at: https://scholar.uwindsor.ca/biologypub

Part of the Biology Commons

\section{Recommended Citation}

Marteinson, S. C.; Drouillard, K. G.; and Verreault, J., "Short-term fasts increase levels of halogenated flame retardants in tissues of a wild incubating bird" (2016). Environmental Research, 146, 73-84. https://scholar.uwindsor.ca/biologypub/754

This Article is brought to you for free and open access by the Department of Biological Sciences at Scholarship at UWindsor. It has been accepted for inclusion in Biological Sciences Publications by an authorized administrator of Scholarship at UWindsor. For more information, please contact scholarship@uwindsor.ca. 
1 Short-term fasts increase levels of halogenated flame retardants in tissues of a wild

2 incubating bird

4 Sarah C. Marteinson ${ }^{1}$, Ken G. Drouillard ${ }^{2}$ and Jonathan Verreault ${ }^{1 *}$

$6 \quad{ }^{1}$ Centre de recherche en toxicologie de l'environnement (TOXEN), Département des sciences

7 biologiques, Université du Québec à Montréal, C.P. 8888, Succursale Centre-ville, Montreal,

8 QC, Canada, H3C 3P8

$9 \quad{ }^{2}$ Great Lakes Institute for Environmental Research (GLIER), University of Windsor, 401 Sunset

10 Avenue, Windsor, ON, Canada, N9B 3P4

11

$12{ }^{*}$ Corresponding author. Mailing address: Département des sciences biologiques, Université du

13 Québec à Montréal, C.P. 8888, Succursale Centre-ville, Montréal, Québec, H3C 3P8, Canada.

14 Tel. +514-987-3000 ext. 1070; Fax: +514-987-4647; E-mail address:

15 verreault.jonathan@uqam.ca

16

17 
Many species are adapted for fasting during parts of their life cycle. For species undergoing extreme fasts, lipid stores are mobilized and accumulated contaminants can be

21 released to exert toxicological effects. However, it is unknown if short-term fasting events may

22 have a similar effect. The objective of this study was to determine if short successive fasts are

23 related to contaminant levels in liver and plasma of birds. In ring-billed gulls (Larus

24 delawarensis), both members of the pair alternate between incubating the nest for several hours

25 (during which they fast) and foraging, making them a useful model for examining this question.

26 Birds were equipped with miniature data loggers recording time and GPS position for two days

27 to determine the proportion and duration of time birds spent in these two activities. Liver and

28 plasma samples were collected, and halogenated flame retardants (HFRs) (PBDEs and

29 dechlorane plus) and organochlorines (OCs) (PCBs, DDTs, and chlordane-related compounds)

30 were determined. Most birds (79\%) exhibited plasma lipid content below 1\%, indicating a likely

31 fasted state, and plasma lipid percent declined with the number of hours spent at the nest site.

32 The more time birds spent at their nest site, the higher were their plasma and liver concentrations

33 of HFRs. However, body condition indices were unrelated to either the amount of time birds

34 fasted at the nest site or contaminant levels, suggesting that lipid mobilization might not have

35 been severe enough to affect overall body condition of birds and to explain the relationship

36 between fasting and HFR concentrations. A similar relationship between fasting and OC levels

37 was not observed, suggesting that different factors are affecting short-term temporal variations in

38 concentrations of these two classes of contaminants. This study demonstrates that short fasts can

39 be related to increased internal contaminant exposure in birds and that this may be a confounding

40 factor in research and monitoring involving tissue concentrations of HFRs in wild birds. 
42 Keywords: PBDEs; PCBs; Dechlorane Plus; lipid mobilization; Fasting; birds; incubation

43

\section{$44 \quad$ Funding sources}

45 Natural Sciences and Engineering Research Council of Canada (NSERC: grant \#385787) (J.V.)

46 Canada Research Chair in Comparative Avian Toxicology (grant \#225707 J.V.)

47 Fonds québécois de la recherche sur la nature et les technologies (to S.C.M.).

50 Research Approval

51 All experimental protocols with the ring-billed gull were approved by the Institutional

52 Committee on Animal Care of the Université du Québec à Montréal. 


\section{Introduction}

54 For many vertebrate species, chronic and short term fasting occurs regularly as part of their

55 life cycle such as during hibernation, post-weaning, incubation, moulting, and migration, or can

56 be part of regular seasonal restrictions in food availability or foraging frequency. During periods

57 of fasting or starvation, animals mobilize lipid reserves to fuel their daily energy requirements.

58 Depending on the species, body state and size of lipid stores, this metabolic state can last

59 anywhere from several hours to months (Wang et al. 2006). Because many halogenated organic

60 contaminants are predominantly lipid soluble and thus bioaccumulative in lipid-rich tissues, they

61 can be released through lipid mobilization leading to increased circulating levels (Birnbaum

62 1985). Studies to date on the effects of fasting on contaminant toxicodynamics in free-ranging

63 animals have focused mainly on species that undergo dramatic fasting events where individuals

64 loose a large proportion of their total body lipids such as polar bears (Ursus maritimus) during

65 hibernation (Polischuk et al. 2002) and female eider ducks (Somateria mollissima) that fast for

66 several weeks during incubation (Bustnes et al. 2010). In these situations, lipid mobilization

67 during fasting can lead to increased circulating levels of contaminants as they are released from

68 fat stores (Birnbaum 1985). Several studies have reported increased enzyme-mediated liver

69 metabolism of contaminants following fasting, further confirming that increased organismal

70 exposure occurs during these natural food deprivation phases (Helgason et al. 2010; Jorgensen et

71 al. 1999; Routti et al. 2013; Vijayan et al. 2006).

72 The effects of less severe fasting events on contaminant concentrations in birds have received

73 limited attention to date particularly for wildlife species undergoing mild fasting events. Many

74 birds are not adapted for long-term fasting and thus they must forage frequently to cover their

75 high daily energy requirements. In such species, even short-term or milder fasts have the 
76 potential to enhance lipid mobilization, which may as a result impact internal contaminant

77 concentrations (e.g. Routti et al. 2013). However, herring gull chicks (Larus argentatus)

78 exposed to a mixture of environmental contaminants and subsequently fed a reduced (by $70 \%$ )

79 but not fully restricted diet for one week, demonstrated a $10 \%$ loss in body lipids coupled with an

80 increase in contaminants and their metabolites in liver, brain, and plasma (Routti et al. 2013).

81 This study showed that even incomplete fasting can reduce body fat stores, increase lipid

82 mobilization and associated contaminant release in birds that are not adapted for high lipid

83 storage. Conversely, white crowned sparrows (Zonotrichia leucophrys) exposed to 1,1,1-

84 trichloro-bis(4-chlorophenyl)ethane ( $p, p^{\prime}$-DDT) in the lab for 5 days and subsequently fasted did

85 not show increases in $p, p^{\prime}$-DDT or its metabolites, $p, p^{\prime}$-DDD and $p, p^{\prime}$-DDE, in various tissues

86 following 20 minute, 4 or 9 hour fasting regimes despite the loss of up to $19 \%$ of their body

87 mass (Scollon et al. 2012). Further research on different contaminants, in different species and

88 under varying fasting regimes is clearly needed to resolve this question.

89 Once fat-soluble contaminants are released from their association with lipids, they enter

90 circulation and may be redistributed into target organs and tissues to exert toxicity (e.g. Bigsby et

91 al. 1997). This means that during periods of fasting, animals may be at an increased risk of

92 adverse effects which may be compounded by other ecological and physiological challenges

93 including or resulting from food shortage (Wingfield 1994), migration, reproduction, or disease

94 (Hall et al. 2008; Keller et al. 2006). Which species are at increased risk of exposure from

95 contaminant release from fat stores, and in what life cycle phases this may occur, are still not

96 well understood nor are the toxicokinetics of different contaminant classes in this situation.

97 The objective of the present study was to determine if short successive fasts related to

98 incubation bouts were linked to contaminant (chlorinated and brominated) concentrations in liver 
99 and plasma of an omnivorous bird species, the ring-billed gull (Larus delawarensis). We used

100 ring-billed gulls breeding near the metropolis of Montreal (QC, Canada) because they have been

101 shown to accumulate elevated levels of halogenated flame retardants (HFRs) (Gentes et al.

102 2012). Moreover, this species undergoes biparental incubation (Ryder 2012), where both parents

103 alternate between bouts of incubation (and thus fasting) that may last several hours, and foraging

104 trips (Marteinson et al. 2015). Because these gulls do not exhibit prolonged continuous fasts

105 (e.g., several days), we measured their time-activity budget using high-resolution GPS-based

106 tracking during the last 24 hours prior to tissue collection. The relationships between liver and

107 plasma contaminant concentrations and the amount of time spent fasting at the nest site or

108 foraging away from the colony were investigated. To evaluate whether or not birds were in a

109 fasted state, the percent plasma lipids was assessed, and the body condition was examined. We

110 hypothesized first that, $i$ ) if short term fasting was to elicit lipid mobilization and increased

111 contaminant release from lipid stores that contaminant concentrations would increase in plasma

112 and liver as a function of the duration of time birds spend fasting at the nest site, and ii) that this

113 increase would be related to changes in whole body lipid stores during fasting. Alternatively, if

114 contaminant concentrations in plasma were dependent largely on recent dietary intake of

115 contaminated prey, HFR and OC concentrations in blood would be expected to decline with the

116 number of hours spent at the nest site (and thus time since feeding), or increase as the proportion

117 of time spent foraging increased, and be related to time spent foraging in habitats of varying

118 contamination.

120 Materials and Methods

$121 \quad$ Model species and fieldwork 
123 females $(n=13)$ were sampled on Deslauriers Island $\left(45^{\circ} 42^{\prime} 45^{\prime}{ }^{\prime} \mathrm{N}, 73^{\circ} 26^{\prime} 25^{\prime}\right.$ ' W) located in the

124 St. Lawrence River downstream of Montreal (QC, Canada). Approximately 44,000 ring-billed

125 gull pairs breed on this island annually (P. Brousseau, personal communication). These

126 omnivorous gulls use the surrounding mosaic of agricultural, urban and suburban areas where

127 they feed opportunistically (Patenaude Monette et al., 2014; Caron-Beaudoin et al., 2013). The

128 most prominent HFRs previously determined in these ring-billed gulls were PBDEs, for which

129 the sum of 45 congeners averaged ( \pm SEM) $205 \pm 32.0 \mathrm{ng} / \mathrm{g}$ wet weight (ww) in liver and $27 \pm$

$1304.05 \mathrm{ng} / \mathrm{g} \mathrm{ww}$ in plasma, which is the highest level recorded in gull tissues to date in Canada

131 (Gentes et al. 2012). Dechlorane plus (DP), a suggested deca-BDE alternative, was also

132 determined in all of the samples at low levels in liver (anti-DP: $6.06 \pm 1.64 ;$ syn-DP: $2.38 \pm 0.67$;

133 (Gentes et al. 2012).

134 Two-hundred ring-billed gull nests with one egg were georeferenced and monitored

135 daily. Once clutches were completed (i.e., three eggs), males or females were initially captured

136 at random on their nests using a radio-controlled noose trap and the number of incubation days

137 completed was back calculated. Each bird was weighed $( \pm 0.01 \mathrm{~g})$ and morphometric

138 measurements (head, culmen, and tarsus length) were recorded using digital callipers $( \pm 1 \mathrm{~mm})$.

139 A miniature GPS data logger (GiPSy2, TechnoSmArt, Guidonia, Roma, Italy) was then attached

140 on two central tail feathers (rectrices), and was recovered at the second capture two to three days

141 later. GPS units weighed 14-15 g, thus representing 2-4\% of the ring-billed gull's body mass

142 (mean \pm SEM: $478 \pm 7 \mathrm{~g}$ ), which was shown not to influence the daily energy expenditure (via

143 field metabolic rate measurement) of ring-billed gulls for the same individuals as utilized in the

144 present study (Marteinson et al. 2015). At the initial and second captures, both occurring during 
145 the incubation phase, blood samples were obtained $(3 \mathrm{~mL}$ and $8 \mathrm{~mL}$ for capture and recapture,

146 respectively) using a heparinized 25-gauge needle and $10 \mathrm{~mL}$-syringe. Because blood collection

147 volume from the initial capture had to be restricted due to the body size of these birds and

148 because their behaviour was monitored thereafter, contaminant analysis in blood was only

149 performed on one blood sample set (the second). Following the second blood collection, birds

150 were euthanized, sexed by gonadal examination, and the liver was collected. Adipose tissue was

151 not harvested because it is not reliably present in large enough amounts in this species during the

152 incubation phase (it is sparsely distributed), thus precluding chemical analysis in all individuals.

153 In the field, blood samples were kept in amber plastic vials in a cooler, and were centrifuged in

154 the laboratory within 10 hours to obtain plasma for chemical analysis (section 2.4). Liver

155 samples were also kept in a cooler in the field, and stored at $-20^{\circ} \mathrm{C}$ until chemical analysis

156 (section 2.4). Approval for all handling and sampling procedures was obtained by the

157 Institutional Committee on Animal Care of the Université du Québec à Montréal, which

158 followed the Canadian Council on Animal Care guidelines.

Time-activity budget determination

The same ring-billed gull individuals were used as those for which details on the activity

161 budget and field metabolic rate have been previously reported (Marteinson et al. 2015). Briefly,

162 the GPS data loggers recorded geographical positions $( \pm 5-10 \mathrm{~m})$, velocity, date, and time at 4-

163 minute intervals for two to three days (Caron-Beaudoin et al. 2013). Using combined

164 information on velocity and position, each position was treated as an instantaneous behavioral

165 sample for which the total time duration could be associated following Marteinson et al. (2015).

166 Positions falling into the two activities of interest to address the present objective were defined

167 as follows: 1) "Nest-site attendance" was assigned to all positions when birds were at the nest 
168 site which included incubation as well as time spent near the nest (e.g., resting, guarding and/or

169 preening), as the two behaviors could not be distinguished due to the spatial precision of the GPS

170 data logger; and 2) "Foraging" was assigned to all positions when birds were away from the

171 colony, but not flying. This coarse definition was used because specific activities such as

172 walking, resting or preening similarly could not be distinguished (Marteinson et al. 2015).

173 Though birds were GPS-tracked for 2-3 days, we assessed only positions from the last 24 hours

174 prior to recapture. As a result, the first portion of each trajectory post-release (1-2 days) was not

175 used in this experiment and any potentially confounding behavioural effects related to the initial

176 capture (contention and handling) did not affect activity assessment. From the trajectories within

177 the 24 hours prior to recapture, the proportions (\%) of time spent in each of the two activities

178 were calculated. Because birds were recaptured at the nest site, thus interrupting a bout of nest-

179 site attendance, the number of hours that birds were attending the nest-site prior to recapture

180 could also be determined. The proportion of time birds spent foraging was further categorized

181 into habitat types utilized based on previous research in our laboratory (Caron-Beaudoin et al.

182 2013; Gentes et al. 2015; Marteinson et al. 2015): 1) agricultural areas, 2) waterways (including

183 the St. Lawrence River and other water bodies), and 3) urban areas (including urban, suburban,

184 landfills, and wastewater treatment plant ponds).

\section{Body condition and nutritional state}

The body condition of ring-billed gulls was estimated via two methods. First, the

187 condition index of individuals was determined for each sex separately by plotting the first

188 principal component based on three morphometric measures (head, culmen, and tarsus length)

189 against body mass, from which residuals were obtained and used as body condition index. This

190 measure is useful in estimating body condition which will depend on how both muscle and fat 
masses contribute to overall body mass. Second, body composition was estimated to determine

192 the proportion of whole body lipids. To achieve this the determination of total body water

193 percent by measuring the dilution of deuterium-labelled water in blood after a period of 1 hour

194 following injection (described below) was conducted. Total body water percent has been shown

195 to be a reliable non-destructive technique to estimate body condition in birds (McWilliams and

196 Whitman 2013) and is strongly and negatively correlated with total body lipid content in birds

197 and mammals (Farley and Robbins 1994; Mata et al. 2006) including gulls (glaucous gulls, Larus

198 hyperboreus: (Shaffer et al. 2006); Verreault et al. 2007; Fig. S1). Briefly, as described in detail

199 in Marteinson et al. (2015), at the initial capture, $0.65 \mathrm{~mL}$ of water containing $37 \%$ deuterium

$200(371,000 \mathrm{ppm})$ was injected into the pectoral muscle of the bird and after 1 hour of water

201 equilibration in the body, a $3 \mathrm{~mL}$ blood sample was obtained. Duplicate $500 \mu \mathrm{L}$ aliquot samples

202 of plasma were separated from whole blood and were assessed for ${ }^{2} \mathrm{H} /{ }^{1} \mathrm{H}$ ratio using a

203 Micromass Isoprime ${ }^{\mathrm{TM}}$ DI gas isotope ratio mass spectrometer (IRMS) coupled to a Aquaprep ${ }^{\mathrm{TM}}$

204 system using an equilibration method with the presence of hydrophobic platinum as a catalyst

205 (Horita and Kendall 2004). Baseline levels of deuterium for this field site (colony) were

206 determined from plasma of four control (uninjected) ring-billed gulls. The whole body water

207 percent was calculated by dividing the dilution space for hydrogen (in grams of water) by body

208 mass. The dilution space $\left(\mathrm{N}_{\mathrm{d}}\right)$ was calculated using the plateau approach as follows: $\mathrm{N}_{\mathrm{d}}=\mathrm{Mol}_{\mathrm{inj}}$

$209\left(E_{\text {mix }}-E_{\text {inj }}\right) /\left(E_{\text {wat }}-E_{\text {mix }}\right)$ where $M_{\text {olinj }}$ is the moles of ${ }^{2} \mathrm{H}$ in the injectate, $E_{\text {mix }}$ is the equilibrium

210 enrichment of ${ }^{2} \mathrm{H}$ in water (ppm of initial enrichment), $\mathrm{E}_{\mathrm{wat}}$ is the background level of isotopes

211 from control birds (in ppm) and $E_{\text {inj }}$ is the enrichment of the injectate (in ppm) (eqn 17.11:

212 Speakman 1997). The percent of whole body lipids was then calculated using the linear equation

213 determined for the relationship between total body water mass and total body lipid mass in 
214 glaucous gulls $(\mathrm{y}=-0.91 \mathrm{x}+69.89)$ which were inversely correlated $\left(R^{2}=0.72\right)$ (data from

215 Shaffer et al. 2006 and Verreault et al. 2007; Fig. S1). The extractable percent lipid content was

216 determined in plasma and liver as part of the chemical analysis (see section 2.4), and was used as

217 a measure of recently acquired lipids though diet and as a proxy of fasting state. Plasma lipid

218 content above $1 \%$ were used as a guideline to indicate whether birds had fed recently (K.

219 Drouillard, unpublished data), whereas those below this threshold were likely to be in a fasted 220 state, for example, fasted ring doves were found to have an average of $0.63 \%$ lipids in plasma 221 while fasting (Drouillard and Norstrom 2000).

\section{Chemical analysis}

Ring-billed gull liver and plasma samples (both from the second capture) were analyzed

224 for 37 PBDE congeners (BDE-1, -2, -3, -7, -10, -15, -17, -28, -49, -66, -71, -77, -85, -99, -100, -

$225119,-126,138,-139,-140,-153,-154 / B B-153,-171,-180,-183 /$ Dec-604, -184, -191, -196, -

226 197/-204, -201, -203, -205, -206, -207, -208, and -209) as well as dechloranes (Dec) (Dec-602, -

227 603, BDE-183/-604, and -604 CB), Chlordene Plus (CP) and Dechlorane Plus (syn- and anti-

228 DP). Sample extraction and clean-up procedures were performed based on methods described

229 previously in detail (Houde et al. 2014; Gentes et al 2012). Briefly, $1.0 \mathrm{~g}$ of liver or plasma was

230 homogenized and ground with diatomaceous earth, and spiked with $200 \mathrm{ppb}$ of an internal

231 standard mixture (BDE-30, BDE-156, ${ }^{13} \mathrm{C}-\mathrm{BDE}-209,{ }^{13} \mathrm{C}-$ syn-DP, and ${ }^{13} \mathrm{C}$-anti-DP), and

232 extracted with the solvent dichloromethane: $n$-hexane (50:50 volume ratio) using a pressurized

233 liquid extraction system (Fluid Management Systems, Watertown, MA). The extractable lipid

234 percentages in plasma and liver samples were determined gravimetrically. Samples were

235 cleaned-up with a PBDE-free acid-basic-neutral column followed by a PBDE-free neutral

236 alumina column (Fluid Management Systems). The identification and quantification of the 
237 analytes was achieved using a gas chromatograph coupled to a mass spectrometer (GC-MS)

238 (Agilent Technologies 5975C Series, Palo Alto, CA) in the electron capture negative ionization 239 mode (ECNI). Quality assurance procedures included analysis of method blanks and standard 240 reference material (SRM) (NIST 1947 Lake Michigan fish tissue) for each batch of ten samples.

241 Background contamination of method blanks were low, however, blank correction was

242 consistently performed for the following PBDEs: BDE-15, -17, -47, -49, -66, -71, -77, -85, -99, -

$243100,-119,126,-138,-139,-153,-154 / B B-153,-171,-180,-183 /$ Dec-604, -191, -196, -197/-204,

$244-201,-203$, and -209. The mean recovery of the internal standards in samples, blanks and SRMs

245 were $85.8 \pm 1.7 \%$ for BDE-30, $88.0 \pm 1.9 \%$ for BDE-156, $51.2 \pm 1.9 \%$ for ${ }^{13} \mathrm{C}-\mathrm{BDE}-209,90.0 \pm$

$2462.2 \%$ for ${ }^{13} \mathrm{C}-s y n-D P$ and $90.2 \pm 2.2 \%$ for ${ }^{13} \mathrm{C}$-anti-DP. Concentrations of PBDEs and other

247 HFRs were quantified using an internal standard approach, and thus all analyte concentrations

248 were inherently recovery-corrected. PBDE concentrations (seven congeners) determined in SRM 249 showed less than $22 \%$ deviation from certified values.

Levels of OCs were reanalyzed in cleaned-up fractions obtained from liver tissue only 251 (see sample preparation procedure above) because large enough volumes of plasma could not be 252 collected from these mid-size birds. The compounds measured were: PCBs (CB-17, -18, -33, $25344,-49,-52,-70,-74,-82,-87,-95,-99,-101,-110,-118,-128,-138,-149,-151,-153,-156,-$ $254158,-170,-171,-177,-180,-183,-187,-191,-194,-195,-206,-208$, and -209$)$, 255 dichlorodiphenyltrichloroethane ( $p, p^{\prime}$-DDT) and its metabolites ( $p, p^{\prime}$-DDD, $p, p^{\prime}$-DDE), Mirex, 256 oxychlordane, cis- and trans-nonachlor, cis-chlordane, pentachlorobenzene (QCB),

257 tetrachlorobenzene (1,2,3,4-TCB and 1,2,4,5-TCB), and octachlorostyrene (OCS). The ${ }^{13} \mathrm{C}-$ syn258 DP and ${ }^{13} \mathrm{C}$-anti-DP internal standards were used to recovery-correct OC concentrations as 259 described above. Chemical analysis was performed using a Hewlett-Packard 5890 GC with 5973 
mass selective detector (GC-MSD) operated in the electron impact (EI) mode, and using selected

261 ion monitoring (SIM). For every batch of five samples, a MSD-PCB standard prepared from

262 Aroclor 1242, 1254 and 1260 mixtures (AccuStandards, CT), two OC pesticide standards

263 (Supelco, PA), a method blank and one in-house reference tissue (GLIER Detroit River fish

264 homogenate) were also analyzed. PCB concentrations (32 congeners) determined in the in-house

265 reference tissue showed less than $26 \%$ deviation from reference values.

266 Data analysis

267 The complete data sets (including contaminant concentrations, time-activity budget, body

268 condition indices, and percent lipids) were obtained for 16 males and 13 females for plasma

269 contaminant concentrations and 14 males and 11 females for liver contaminant concentrations.

270 All statistical analyses were conducted using wet weight (ww)-based concentrations of these

271 lipophilic contaminants did not increase in proportion to tissue lipids (Hebert and Keenleyside

272 1995). More specifically, for liver samples, HFR concentrations were unrelated to liver lipid

273 percents (Pearson's Correlation Analysis; $0.982>p>0.140$ ), which was consistent with OC

274 concentrations (Spearman's Correlation Analyses; $0.810>p>0.071$ ). Plasma HFR

275 concentrations, were correlated with plasma lipid percents (see results below), although

276 negatively, and thus opposite to what is predicted for lipophilic contaminants according to

277 Hebert and Keenleyside (1995). Regardless, a parallel set of relationships between lipid percents

278 and plasma HFR concentrations based on lipid-normalized data are presented in the

279 Supplementary Information (Fig. S5) which demonstrates similar results to those based on ww

280 concentrations. For HFRs, PBDE congeners that were determined (i.e. above the detection limit)

281 in both liver and plasma of all individuals as well as the sum of all analyzed congeners

282 ( $\Sigma_{37}$ PBDEs) were used in analyses. The $\Sigma_{37}$ PBDEs were calculated by summing the 
283 concentrations of all congeners above their respective detection limits. The sum of dechloranes

284 was also assessed which, depending on their detection, for plasma included levels of syn-and

285 anti-DP, and for liver it additionally included Dec-602, -603, and -604 CB as well as CP. For

286 OCs, PCB congeners that were quantified in liver of all individuals were also analyzed as were

$287 \Sigma_{38} \mathrm{PCBs}, p, p$ '-DDE, $p, p^{\prime}$-DDT, and $\sum$ nonachlors (sum of cis- and trans-nonachlor).

288 Relationships between contaminant concentrations (plasma or liver) and the following

289 variables were assessed using Spearman's Rank Correlation analyses: percent lipids in either

290 liver or plasma, body condition measures (body condition index, whole body water and lipid

291 percents), activity measures (time spent incubating or foraging and number of hours spent at the

292 nest-site prior to recapture); correlation analyses between body condition and activity measures

293 or the number of incubation days completed were also assessed. Spearman's Rank Correlation

294 analyses were used for both sexes combined due to low sample size and to control for the effect

295 of any outliers due to the ranking of the data. The contaminants were listed in order of

296 decreasing $r$ value to rank the strength of the relationships because different congeners will have

297 varying halogenation and lipophilicity (expected to show differing behaviour during fasting).

298 Data were additionally split into two groups defined as follows, and compared for contaminant

299 concentrations and condition measures using t-tests: 1) birds in the lower (25\%) and upper

300 (75\%) quartile groups based on percent plasma lipids and 2) birds in the lower (25\%) and upper

301 (75\%) quartile groups based on hours spent in nest-site attendance.

To determine and rank which factors influenced the sum concentrations of the contaminant

303 classes, a series of Generalized Linear Models (GLZ) were conducted and ranked using Akaike's

304 Information Criterion corrected for small sample sizes (AICc) (Burnham and Anderson 2002;

305 Burnham et al. 2011). Variables that may affect contaminant levels were assessed including 
306 temporal variables (capture date, Julian egg laying date), sex, body mass, \% plasma lipids, and

307 activity and body condition measures (body condition index, whole body water and lipid

308 percents). Only models with one or two predictor variables as well as the intercept were

309 conducted due to the low sample size. Related variables were not included in the same model.

310 For comparison, the null model was assessed, and only models with $\mathrm{AIC}_{\mathrm{c}}$ values lower than that

311 of the null model were retained. Additionally, models for which predictor variables for which the

312 parameter estimate $95 \%$ confidence intervals included zero were not considered. For each model,

313 the $\triangle \mathrm{AICc}$ was calculated as well as the weight (w) (Burnham and Anderson 2002). Simple

314 linear regressions were also conducted with the variables for each model to generate adjusted $R^{2}$

315 values. Statistical analyses were conducted using IBM SPSS 20, and a 0.05 significance level

316 was employed where applicable. Means are reported with standard error ranges.

\section{Results}

318 Time-activity budget

319 The proportions of time ring-billed gulls spent in nest-site attendance and foraging were 320 consistent with those previously reported for a larger set of individuals including the present

321 birds (Marteinson et al. 2015). Birds spent 47-90\% of the 24-hour tracking period prior to 322 recapture in nest-site attendance (mean: $70 \pm 0.02 \%$ ). The amount of time that birds had spent in 323 this activity prior to their recapture at the nest ranged from 0.2 to 18.9 hours (mean: $5.4 \pm 0.2 \mathrm{~h}$ ). 324 Birds spent from 0 to $30 \%$ of the tracking period in foraging activities (mean: $11 \pm 0.02 \%$ ). The 325 proportions of time ring-billed gulls spent foraging in different sites were consistent with those 326 previously reported for a larger set of individuals, including the present birds (Gentes et al.

327 2015). Gulls in the present sub-sample spent $70 \pm 0.1 \%$ of time foraging in agricultural areas, 29 
$328 \pm 0.06 \%$ in urban areas and $1 \pm 0.01 \%$ of their time on waterways in the last 24 hours prior to

329 capture. Activities were unrelated to body condition measures (condition index, whole body

330 water or lipid percent).

\section{Contaminant concentrations and profiles in liver and plasma}

Concentrations of HFRs (PBDEs and DP isomers) in the present ring-billed gull plasma

333 and liver samples collected in 2011 were comparable to those previously reported for individuals

334 sampled in 2010 (Gentes et al. 2012). The mean $\sum_{37}$ PBDE concentrations in the present ring-

335 billed gulls were $138 \pm 22.2 \mathrm{ng} / \mathrm{g} \mathrm{ww}$ in liver (Fig. 1) and $32.7 \pm 4.7 \mathrm{ng} / \mathrm{g} \mathrm{ww}$ in plasma. Among

336 these, 13 PBDE congeners were quantifiable in all individuals in both liver and plasma including

337 tetra-BDE (BDE-47), penta-BDEs (BDE-99 and -100), hexa-BDEs (BDE-138, -153, and -

338 154/BB-153), hepta-BDE (BDE-183), octa-BDEs (BDE-196, -197, and -201), nona-BDEs

339 (BDE-207 and -208), and deca-BDE (BDE-209). This congener profile was dominated by BDE-

340209 , followed by the major penta-mixture congeners BDE-99, $-47,-153$, and -100 in descending

341 order in both liver and plasma (Fig. S2). The percent contributions of these five major congeners

342 to $\Sigma_{37} \mathrm{PBDE}$ concentrations in liver samples (with almost identical proportions in plasma) were

$34326 \pm 2 \%, 24 \pm 1 \%, 18 \pm 1 \%, 7 \pm 0.4 \%$ and $6 \pm 0.4 \%$, respectively. The $\Sigma$ dechlorane

344 concentrations were $6.6 \pm 1.3 \mathrm{ng} / \mathrm{g}$ ww in liver (Fig. 1) and $0.5 \pm 0.1 \mathrm{ng} / \mathrm{g}$ ww in plasma.

345 Several OCs were detected in ring-billed gull liver samples. The mean $\Sigma_{38} \mathrm{PCB}$

346 concentrations in the gull livers were $138 \pm 16.1 \mathrm{ng} / \mathrm{g} \mathrm{ww}$ (Fig. 1). A total of 19 PCB congeners

347 were detected in the liver of all individuals, which included penta-CBs (CB-99, -118, -105, and -

348 128), hexa-CBs (CB-138, -153, -158, and -156), hepta-CBs (CB-170, -171, -180, -183, and -

349 191), octa-CBs (-194, -195, and -199) and the nona-CB-206. The congeners present in the 
highest concentrations were CB-153, -138, -180, -187 and -118 in descending order (Fig. S3).

351 Several other OCs were quantified in liver of all individuals (Fig. 1): trans-nonachlor (mean:

$35210.8 \pm 1.7 \mathrm{ng} / \mathrm{g} \mathrm{ww})$, cis-nonachlor $(0.7 \pm 0.2 \mathrm{ng} / \mathrm{g} \mathrm{ww}), p, p^{\prime}-\mathrm{DDE}(107 \pm 12.3 \mathrm{ng} / \mathrm{g} \mathrm{ww})$, and

$353 p, p$ 'DDT $(33.9 \pm 4.7 \mathrm{ng} / \mathrm{g} \mathrm{ww})$ (Fig. 1). A few other OCs were detected in some of the

354 individuals including QCB $(n=8)$, cis-chlordane $(n=7), p, p^{\prime}$-DDD $(n=5)$, Mirex $(n=16)$, and

355 trans-chlordane $(n=1)$, whereas 1,2,4,5-TCB, 1,2,3,4-TCB, OCS, and oxychlordane were not

356 detected in any individuals. Mean concentrations of $\sum_{37}$ PBDEs in liver were similar to $\Sigma$

$357 \quad{ }_{38} \mathrm{PCBs}$ in this tissue (Fig. 1).

Liver, plasma and whole body lipid contents and contaminant concentrations

The mean extractable plasma lipid percent of ring-billed gulls was $0.8 \pm 0.04 \%$ (range:

$0.07-1.4 \%)$. The majority of birds $(79 \% ; n=23)$ exhibited plasma lipid content below $1 \%$,

361 with six individuals having percent lipids above that fasting state guideline level (Fig. 2).

362 However, the plasma lipid percent declined significantly with the number of hours birds had

363 spent on their nest site prior to recapture $(r=-0.40, p=0.033)$, which corresponded to a $0.02 \%$

364 decline in lipid percentage per hour of nest-site attendance (Fig. 2). Based on the patterns

365 observed, plasma lipid contents between 0.5 and $0.8 \%$ were the most commonly encountered and

366 no birds had plasma lipids exceeding $0.8 \%$ after their nest-site attendance lasted $\geq 8$ hours.

367 The mean liver lipid percent of ring-billed gulls was $6.0 \pm 0.2 \%$ (range: $4.1-8.5 \%$ ). Liver

368 lipid percent was unrelated to the number of hours birds had fasted prior to recapture. Whole

369 body lipid content estimated by the deuterium labelled water method was $23.6 \pm 2.4 \%$ (range:

$370 \quad 17.4-28.3 \%$ ). Similar to what was observed for liver lipids, whole body lipids did not show any

371 significant relationship with the number of hours birds had fasted prior to recapture. 
The plasma lipid percent was negatively associated with the plasma concentrations of

373 several individual PBDEs (in order of decreasing $r$ : BDE-154/BB-153, -209, -47, -196, -197, -

$374201,-208$, and -207; $-0.31<r<-0.37 ; 0.014<p<0.050), \Sigma_{37}$ PBDEs $(r=-0.33, p=0.031)$ (Fig.

$3753 \mathrm{~B})$ as well as $\Sigma$ dechloranes $(r=-0.39, p=0.022)$. Similarly, liver concentrations of several

376 individual PBDE congeners (in order of decreasing $r$ : BDE-183/Dec-604, -153, -154/BB-153, -

$377196,-197 / 204,-100,-47,-201,-209$, and $-138 ;-0.33<r<-0.43 ; 0.007<p<0.046) . \Sigma_{37}$ PBDEs

$378(r=-0.40, p=0.013)($ Fig. 3A) and $\Sigma$ dechloranes $(r=-0.35, p=0.03)$ were also negatively

379 associated with plasma lipid content. Despite the variation in bromine content of the various

380 PBDE congeners (from tetra- to deca-brominated) that were related to plasma lipid percent,

381 correlations all showed a very similar $r$, and thus only the relationships between plasma lipid

382 percents and $\Sigma_{37}$ PBDEs in liver or plasma are displayed graphically for brevity (Fig. 3). Birds

383 with low plasma lipid percents $(25 \%$ quartile; $n=13)$ ranged from $0.4-0.7 \%$ and those with high

384 plasma lipid percents $(75 \%$ quartile, $\mathrm{n}=11)$ had mean levels above the $1 \%$ threshold $(0.93$ -

$3851.43 \%$ ). The mean $\Sigma_{37} \mathrm{PBDEs}$ in liver and plasma of low plasma lipid birds was $74.4 \pm 19.4 \mathrm{ng} / \mathrm{g}$

386 ww and $41.0 \pm 6.7 \mathrm{ng} / \mathrm{g}$ ww which were 2.3 and 2.1 times higher, respectively, compared to high

387 lipid plasma birds (mean liver: $33.1 \pm 10.7 \mathrm{ng} / \mathrm{g} \mathrm{ww}$; plasma: $19.4 \pm 4.6 \mathrm{ng} / \mathrm{g} \mathrm{ww}$ ). The

388 difference between low and high plasma lipid birds was significant for $\Sigma_{37}$ PBDEs in plasma $\left(t_{22}\right.$

$389=2.55, p=0.018)$ with a similar, but non-significant trend for liver concentrations $\left(t_{18}=1.86, p\right.$

$390=0.079)$.

$391 \quad$ PCB and OC pesticide concentrations in liver were not significantly related to the lipid

392 percents in plasma (Fig 3). For these compounds, birds grouped into low plasma lipid categories

393 showed mean $\sum_{38} \mathrm{PCB}$ concentration of $161 \pm 51.5 \mathrm{ng} / \mathrm{g} \mathrm{ww}$ in liver compared to $134 \pm 32.0 \mathrm{ng} / \mathrm{g}$ 
394 for birds in the high plasma lipid category, representing a 1.2 times decrease which did not differ 395 significantly.

Relationships between contaminant concentrations and time-activity budget

With respect to the HFRs, as the proportion of time that birds spent in nest-site attendance increased, so did their concentrations of $\Sigma_{37} \mathrm{PBDEs}$ in both liver $(r=0.49, p=0.013)$

400 and plasma $(r=0.44, p=0.020)$. Several of the major congeners in liver (in order of decreasing $401 \quad r$ : BDE-99, -197/204, -201, -209, -153, -47, -154/BB-153, -196, -183/Dec-604, -138, -208, -100, 402 and -207: $0.49<r<0.57 ; 0.003<p<0.033$ ) and plasma (in order of decreasing $r$ : BDE-100, $403153,-154 /$ BB- $153,-47,-209,-153$, and $-99: 0.39<r<0.43 ; 0.022<p<0.042)$ also significantly 404 increased with the proportion of time birds spent in nest-site attendance. The positive correlation 405 between nest-site attendance and $\Sigma_{37} \mathrm{PBDE}$ concentrations was stronger when the number of 406 hours at the nest site before recapture was considered for both liver $(r=0.56, p=0.004$; Fig. 4A) 407 and plasma concentrations $(r=0.57, p=0.002$; Fig. 4B, with a similar figure for lipid-corrected 408 values in plasma: Fig. S5). $\Sigma_{37}$ PBDE concentrations in this sub-sample of the colony increased 409 on average by $18.0 \mathrm{ng} / \mathrm{g}$ ww per hour spent on the nest site prior to capture in liver and $2.5 \mathrm{ng} / \mathrm{g}$ 410 ww on average per hour in plasma (Fig. 5). Most of the major congeners in liver (in order of 411 decreasing $r$ : BDE-153, -154/BB-153, -138, -99, -100, -197/-204, -209, -201, -183/Dec-604, 412 196, -207, and -47: $0.44<r<0.60 ; 0.001<p<0.033$ ) and plasma (in order of decreasing $r$ : 413 BDE-209, -154/BB-153, -153, -99, -153, -100, -47, -196, -197, -207, -208, and -201: $0.41<r<$ $4140.57 ; 0.002<p<0.032)$ also increased with the number of hours spent at the nest site before 415 recapture. Additionally, $\Sigma$ dechlorane concentrations in liver were positively related to the 416 proportion of time spent at the nest-site $(r=0.40, p=0.050)$. Birds with low nest site attendance 
417 (25\% quartile, $\mathrm{n}=7$ ) were present at the nest site for 1.5 hours or less (mean: $0.8 \pm 0.4)$ and

418 those with high nest-site attendance $(75 \%$ quartile, $n=7)$ were present at the nest for 7.3 hours or

419 more (mean: $13.2 \pm 1.6 \mathrm{~h}$ ). Low nest-site-attendance birds exhibited a mean $\sum_{37} \mathrm{PBDE}$

420 concentrations of $14.7 \pm 3.0 \mathrm{ng} / \mathrm{g}$ ww in plasma and $52.7 \pm 13.2 \mathrm{ng} / \mathrm{g} \mathrm{ww}$ in liver which were 3.8

421 and 5.2 times lower, respectively, compared to those in the high nest-site attendance group

422 (mean plasma: $56.2 \pm 15.4 \mathrm{ng} / \mathrm{g} \mathrm{ww}$; mean liver: $275 \pm 105 \mathrm{ng} / \mathrm{g} \mathrm{ww}$ ). Concentrations of OCs

423 were unrelated to nest-site attendance measures or the proportion of time spent foraging. Similar

424 to what was reported by Gentes et al. (2015) for a larger set of ring-billed gulls (which included

425 the present individuals), the proportion of time spent foraging in agricultural and urban areas as

426 well as in waterways were not related to HFR concentrations. Similarly, OC concentrations in

427 liver were unrelated to the proportion of time spent in these three different foraging habitats.

\section{$428 \quad$ Relationships with body condition measures}

429 Body condition index (mean: $-0.71 \pm 3.74 \mathrm{~g}$ ), total body water percent (mean: $51 \pm$

$430 \quad 0.42 \%$ ) and total body lipid percent (mean: $23.61 \pm 0.38 \%$ ) were not related to nest-site

431 attendance measures, proportion of time spent foraging, number of incubation days completed or

432 contaminant concentrations, nor were they related to one another.

434 Model selection for $\Sigma$ PBDEs in liver and plasma

435 AIC analysis was conducted exclusively for PBDEs because only this contaminant class

436 showed relationships with predictor variables as described above (Table 1). The variation in

437 liver concentrations of $\sum_{37}$ PBDEs were best explained by the model including the number of

438 hours spent at the nest-site prior to recapture in combination with the capture date $(w=0.43)$, 
439 which explained $38 \%$ of the variation. The remaining models that showed significant effects all

440 had considerably lower AIC weights in comparison to the top models $(w=0.12-0.02)$

441 demonstrating their minimal effect on liver $\sum_{37}$ PBDEs in models containing plasma lipid \% $(w$

$442=0.11-0.05)$ and the sex $(w=0.02)$. The variations in $\Sigma_{37}$ PBDEs concentrations in plasma

443 were best explained by the proportion of time birds had spent in nest-site attendance $(w=0.29)$

444 which accounted for $18 \%$ of the variation. The second best model closely followed and was the

445 same as the top model for $\sum_{37} \mathrm{PBDEs}$ in liver- i.e., the number of hours spent at the nest-site in

446 combination with capture date $(w=0.22)$. After these two top models, AIC weights ranged from

$447 \quad 0.15$ to 0.07 , thus comparatively having a minimal effect on plasma $\Sigma_{37} \mathrm{PBDE}$ concentrations.

448 Sex explained only a small proportion of the variations in plasma $\Sigma_{37}$ PBDEs $(w=0.15)$. Julian

449 lay date, body mass and measures of body condition did not explain any variation in $\sum_{37} \mathrm{PBDE}$

450 concentrations in both plasma and liver. Plasma \% lipids did not explain any variation in plasma

$451 \quad \Sigma_{37}$ PBDEs.

\section{Discussion}

453 This study demonstrates that time-activity budgets of wild birds can influence their

454 contaminant concentrations in liver and plasma. More specifically, the percentage of time spent

455 in nest-site attendance, rather than the time engaged in foraging activities, was significantly

456 related to increased plasma and liver concentrations of PBDEs and DP isomers in ring-billed

457 gulls during the incubation period. This suggests that short nest-site attendance bouts in birds

458 have a greater and previously underestimated influence on within-tissue concentration variations

459 compared to foraging, at least with respect to HFRs. However, unexpectedly, a similar pattern of

460 enrichment of OCs in liver as a function of time spent in nest-site attendance did not occur 
461 despite the fact that $\log \mathrm{K}_{\mathrm{ow}}$ values of the contaminant classes are largely overlapping: e.g., 4.6-

4626.9 for PCBs (Han et al. 2006), 5.75 for DDT (Veith et al. 1979), and 5.7-8.3 for PBDEs

463 (Braekevelt et al. 2003; Han et al. 2006). This may imply different causal factors contributing to

464 short-term temporal variations in tissue-specific contaminant levels between present suite of OCs

465 and HFRs. Plasma lipids decreased with time spent fasting as would be predicted, and HFR

466 concentrations increased with time spent fasting which agrees in part with our first hypothesis.

467 However, this did not occur concurrently with the required changes in body condition during

468 fasting in these gulls, that is, there was no relationship between whole body lipids and time spent

469 fasting (incubating) or HFR concentrations. Therefore, we must reject our first hypothesis that

470 short-term fasting caused whole body lipid mobilization and contaminant release in these

471 incubating gulls. The lack of relationship between time spent foraging or in different habitats,

472 which should have varying contamination (e.g. urban vs. agricultural), with plasma or liver HFR

473 or OC concentrations implies that we must also reject our second hypothesis predicting that

474 recent intake of a contaminated diet may be at the basis for the relationships between HFRs and

475 time spent fasting in these birds. These results suggest that other underlying mechanisms may

476 explain the relationships between HFR concentrations and time spent fasting (incubating) in

477 ring-billed gulls. These other possible mechanisms may be related to the effect of time of capture

478 during the incubation phase or differing depuration rates related to metabolic biotransformation

479 of individual PBDE congeners in the gulls. Further study on these avenues and others is

480 warranted and larger sample sizes are needed.

481 Few studies have been conducted on the effects of fasting on contaminant concentrations in

482 birds. A few examples demonstrate that concentrations of contaminants increase during

483 prolonged periods of food restriction. For example, in common eiders, where the female fasts 
484 continuously for four weeks during the incubation, levels of PCB-153, p,p'-DDE and

485 hexachlorobenzene increased between day five and day 20 in the incubation period (Bustnes et 486 al. 2010). Moreover, in overwintering greater scaup (Aythya marila), which experience reduced 487 availability and simultaneous reductions in body fat stores, individuals captured later in the 488 winter had higher wet weight-based levels of $\Sigma$ PCBs and $\Sigma$ DDTs (including DDD, DDE) than 489 birds caught early in the winter (Perkins and Barclay 1997). This effect has been confirmed even 490 in species that are not adapted for extreme fasts. For instance, herring gull chicks exposed to a 491 mixture of contaminants (OCs and PBDEs) in the laboratory and subsequently fasted for one 492 week, exhibited contaminant concentrations that were three times higher in liver, plasma, and 493 brain compared to a non-fasted exposed group (Routti et al. 2013). Changes in feeding rates and 494 body mass throughout the breeding season have similarly been associated to contaminant 495 concentrations in some seabirds, both those adapted to long fasts or not, including kittiwakes 496 (Rissa trydactyla) (Henriksen et al. 1996), and Adélie penguins (Pygoscelis adeliae) and 497 southern fulmars (Fulmarus galacialoides) (van den Brink et al. 1998). More specifically, in the 498 penguin and fulmar study, lower body mass during times of fast (egg-laying or incubation) or 499 times of higher physical exertion (chick-provisioning) were associated with higher levels of 500 several OCs in blood and uropygial oil compared to periods where birds were able to replenish 501 fat stores (van den Brink et al. 1998). Similarly for the kittiwakes during breeding, levels of $502 \Sigma \mathrm{PCBs}$ in the brain were four-fold higher at the end of chick-rearing period during which they 503 lost 20\% of their body mass compared to the pre-breeding period (Henriksen et al. 1996).

504 Collectively, these studies demonstrate that relationships exist between fasting and contaminant 505 concentrations, but the processes behind these remain difficult to explain. 
Contaminant mobilization during tissue lipid metabolism is commonly invoked as a

507 mechanism describing the increase in tissue contaminant concentrations post-fasting (Daley et al.

508 2014). When animals cannot obtain energy from food, they must draw upon stored energy

509 reserves. The loss of lipids due to metabolism of triglycerides stored in adipose tissue, which

510 reflects the main proximate component contributing to the partitioning capacity of organisms for

511 hydrophobic contaminants, results in a fugacity gradient between adipose tissue and blood. This

512 favors net diffusion of chemicals from adipose tissue until a new inter-tissue equilibrium is

513 achieved. The process of lipid mobilization during fasting typically follows a defined sequence

514 of events. In the first metabolic phase of fasting, stored liver glycogen and fatty acids from fat

515 stores are used to supply glucose to tissues (Wang et al. 2006). However, these sources of

516 energy are rapidly depleted (from hours to days) after which the organism will enter the second

517 phase of food deprivation in which glycerol is released from adipose tissue and used for the

518 production of glucose (Wang et al. 2006). This second phase is longer and, depending on the

519 species and size of lipid stores, can last weeks to months (Wang et al. 2006). Fasting birds

520 typically enter phase two after a few days of fasting - two days in red-legged partridges

521 (Alectoris rufai) (Rodriguez et al. 2005) which are not well-adapted to fasting condition, four

522 days in gentoo penguins (Pygoscelis papua) which are adapted to short-term fasts, and seven

523 days in King penguins (Aptenodytes patagonica) which are adapted to several months of fasting

524 (Cherel et al. 1993). Gulls (Larids) fall into the middle of this spectrum, entering phase two after

525 approximately four to five days, as documented for example in herring (Totzke et al. 1999) and

526 yellow-legged gulls (Larus cachinnans) (Alonso-Alvarez and Ferrer 2001).

527 During lipid loss, contaminant levels become concentrated in adipose tissue as lipids are

528 depleted leading to an elevation in chemical fugacity. This creates a fugacity gradient between 
529 adipose and blood that favors chemical diffusion and mobilization from the major storage

530 compartment (fat) to other tissues in the body (Daley et al. 2014). For most bioaccumulative

531 contaminants, inter-tissue distribution kinetics are considered rapid compared to whole body

532 elimination. Therefore, the kinetics associated with tissue-to-tissue transfer are commonly

533 ignored when formulating simple, non-physiologically based bioaccumulation models (Selck et

534 al. 2013). For example, in the ring dove (Streptopelia risoria), rapidly perfused organs such as

535 brain, liver and gonads achieved 90\% steady state with blood PCB-153 in less than three days,

536 while fat and carcass required ten days to achieve steady state with blood (Daley et al. 2013). In

537 contrast, whole body elimination rates for PCB-153 in the same species was reported to be on the

538 order of 2.9 to 3.7 years (Drouillard and Norstrom 2003). The rate at which contaminants are

539 released from fat stores during fasting and how this differs between different chemicals remains

540 largely unknown. Some evidence indicates that not all contaminant classes follow the same

541 dynamics of release during lipolysis. For example, in fasting polar bears, some OCs increased in

542 concentrations in adipose tissue during fasting including $\sum$ chlordanes and PCBs, suggesting that

543 they are less readily released from this compartment, whereas others declined such as EDDTs

544 and $\Sigma$ hexachlorocyclohexanes, suggesting that they were released more easily into circulation

545 and/or were potentially eliminated from the body at a higher rate through metabolic

546 biotransformation (Polischuk et al. 2002). There is some evidence to suggest that contaminants

547 with lower $\log \mathrm{K}_{\text {ow }}$ (i.e., are less lipophilic) may be released more efficiently from blubber in

548 grey seals (Halichoerus grypus) (Vanden Berghe et al. 2012).

549 However, in the present study, there is no evidence to support mobilization of lipid stores

550 as the mechanism behind the relationships between HFR concentrations and time spent fasting.

551 For these birds, the maximum time ring-billed gulls spent on their nesting site was in the order of 
55220 hours, which can be enough to weight loss in birds that are not adapted for prolonged fasting

553 (e.g. Scollon et al. 2012). However, even though individual ring-billed gulls would have

554 underwent several such relatively short fasting events over their 28 days incubation period, there

555 was no relationship between body condition expressed as whole body lipids and time spent at the

556 nesting site, body condition and number of incubation days nor between body condition

557 measures and contaminant concentrations in liver or plasma. This points to a lack of condition

558 deterioration over time during this phase and suggests that these birds remained within the first

559 metabolic phase of fasting, and were relying more heavily on fatty acids and glycogen reserves

560 compared to stored triglycerides. Loss of fatty acids from adipose tissue would also decrease the

561 partitioning capacity of the tissue, but to a lesser extent than triglycerides (Dulfer and Govers

562 1995; Dulfer et al. 1996). Ring-billed gulls forage between short-term incubation bouts, and tend

563 to exploit areas of high and predictable food availability (e.g., anthropogenic-related habitats and

564 agricultural fields) and quality (fat and protein content) (Caron-Beaudoin et al. 2013; Patenaude-

565 Monette et al. 2014). This may have allowed them to replenish labile tissue energy stores as they

566 were used up on a daily basis. This is in line with other seabird species exhibiting biparental care

567 that maintain body mass during the incubation period (e.g., Moreno 1989) despite prolonged

568 bouts of intermittent fasting at the nest. Given that whole body lipids in birds of the present study

569 did not change significantly in relation to time devoted to nest-site attendance, fugacity gradients

570 generated as a result of adipose tissue depletion cannot explain the increasing trend of plasma

571 and liver HFR concentrations with time spent at the nest site. This conclusion is reinforced by

572 the fact that OCs showed no evidence of enriched liver concentrations. Mobilization of

573 contaminants from lipid-rich tissues during weight loss would be expected to increase all

574 hydrophobic contaminant concentrations (including OCs and HFRs in present birds) in tissues to 
575 a similar extent. For example, Routti and colleagues (2013) exposed herring gull chicks to a

576 mixture of environmentally relevant contaminants for 45 days and subsequently fasted (70\%

577 food reduction) treatment birds for seven days to compare chemical enrichment in tissues

578 relative to non-fasted individuals (controls). The above study demonstrated that all contaminant

579 classes including $\Sigma$ PCBs, $\Sigma$ DDTs, $\Sigma$ CHLORs and $\Sigma$ PBDEs increased in liver, brain, and plasma

580 over those of the non-fasted group to a similar extent.

581 It is more likely that the relationships between HFR concentrations and time spent fasting

582 in ring-billed gulls at the nest site was related to recent contaminant exposure which may have

583 changed as the spring season progressed. Three alternative explanations would be that ring-

584 billed gulls had been: i) exposed to a "diluted meal" during foraging activities rather than the

585 contaminated diet we predicted from the habitats they use, ii) exposed to a non-dietary source of

586 HFRs at the nesting site itself or iii) exposure to PBDEs may have altered the incubation

587 behavior of these gulls. In the diluted meal hypothesis, birds returning from foraging and which

588 have fed on a relatively clean meal (low HFR concentrations) would be expected to experience

589 dilution of plasma contamination due to an influx of clean dietary lipids (e.g., portomicrons)

590 and/or production of de novo lipids generated from assimilated nutrients (Drouillard and

591 Norstrom 2000; Drouillard and Norstrom 2001). In this scenario, differences in the behavior of

592 different contaminant classes might be explained by the fact that the diluted meal was less

593 contaminated with HFRs, but not OCs. Based on Fig. 2, peak plasma lipid contents were

594 observed in birds had been incubating for less than a few hours prior to capture, followed by

595 depletion of plasma lipids to apparent fasting levels after eight to ten hours. This profile is very

596 similar to what was observed in ring doves after achieving $\mathrm{C}_{\max }$ of plasma lipids following a

597 controlled feeding study that demonstrated an exponential return of plasma lipids approaching 
598 fasting levels after approximately seven hours (Drouillard and Norstrom 2000). This would be

599 surprising because these birds do not rely heavily on aquatic habitats for feeding which act as

600 sinks for PCBs (reviewed in: Beyer and Biziuk 2009), but they do frequently utilize

601 anthropogenic-related habitats to forage (e.g., Caron-Beaudoin et al., 2013) which can be highly

602 contaminated with HFRs (Venier and Hites 2008). As further evidence, recent (last 24 hours)

603 use of landfills and wastewater treatment plant ponds has been linked to increased concentrations

604 of BDE-209 in these gulls nesting in the same colony as utilized in the present study (Gentes et

605 al. 2015).

606 However, the contaminant patterns in liver of ring-billed gulls do not support this

607 hypothesis. Dilution of liver lipids post-feeding is also possible given that liver is capable of

608 generating lipids from absorbed carbohydrates and proteins. Indeed, lipid-normalized

609 egg/maternal tissue concentration ratios in herring gulls and other bird species have been

610 hypothesized to occur as a result of dilution of the liver lipid pool during yolk production

611 resulting from de novo lipid production in the liver (Braune and Norstrom 1989; Drouillard and

612 Norstrom 2001; Norstrom et al. 1986). In the case of herring gulls, a mean lipid-normalized

613 egg/maternal tissue ratio of 0.7 was apparent, suggesting a 1.4-fold dilution factor of liver OC

614 levels during yolk production (Braune and Norstrom 1989). A much higher egg/maternal tissue

615 dilution factor of 2.9-fold was observed in ring doves which approaches the 5.2-fold differences

616 in liver HFR residues observed in ring-billed gulls from the present study. However, the period

617 of yolk formation is considered an extreme case where de novo lipid production in the liver is

618 expected to be maximized and does not likely reflect the situation present for incubating ring-

619 billed gulls. Second, there was no evidence for a change in liver lipid content with time at the

620 nesting site, which would be expected to be observed under a situation of lipid dilution in liver. 
621 Finally, de novo lipid production by the liver would dilute all hydrophobic chemicals to the same

622 extent, but only HFRs and not OCs showed changes in liver concentration with time on the

623 nesting activity in ring-billed gulls. Thus, the "diluted meal" hypothesis could be considered

624 consistent with the observed trends in plasma concentrations of HFRs and lack of trends for OCs,

625 although not consistent with the patterns observed for liver.

626 The second hypothesis implies that ring-billed gulls were exposed to elevated HFR and

627 baseline OC concentrations while at the nesting site. The exposure source was apparently not

628 related to dietary exposure at the nesting site because the change in plasma lipid content with

629 time at the nest is consistent with birds reverting to a fasting state during this activity.

630 Alternative exposure routes could be as a result of inhaled HFR-contaminated dusts/particles or

631 air at the local nesting site. Assimilated material from the respiratory tract would be expected to

632 show up rapidly in perfused tissues including blood and liver, followed by slower redistribution

633 to adipose tissues (Daley et al. 2013). HFRs can be present in the atmosphere in their volatilized

634 form which is more common for lower-brominated congeners, or in association with

635 dust/particles which is more common for higher-brominated congeners including BDE-209

636 (reviewed in: Hale et al. 2006). Several HFRs including PBDEs have been measured in outdoor

637 air globally (reviewed in: Hale et al. 2006) with the highest concentrations recorded outside

638 point-source areas in urbanized environments (e.g., Venier and Hites 2008). Recently, PBDE

639 concentrations in outdoor air have begun to exceed concentrations of PCBs in several reports

640 (reviewed in: Hale et al. 2006). This is consistent with the finding that the present ring-billed

641 gulls demonstrated similar mean $\Sigma$ PBDEs concentrations to $\Sigma$ PCBs, the latter of which have

642 previously dominated in bird tissue. Few studies have measured HFRs in Canadian city air

643 though, recently in Toronto, air contained $38 \mathrm{pg} / \mathrm{m}^{3} \Sigma$ PBDEs in combined gas and particle 
644 phases, as well as a number of emerging HFRs including syn- and anti-DP (Shoeib et al. 2015).

645 Concentrations of contaminants in the atmosphere can be affected by temperature and weather as

646 well as other atmospheric variables (e.g. (Melymuk et al. 2012) and references therein) and since

647 these change throughout the spring season when incubation takes place in the present location,

648 this may play a role in the identified effect of capture date on PBDE concentrations in these

649 gulls. However, the diet of these birds also changes as the spring progresses (Patenaude-Monette

650 et al. 2014), and further research is required to determine how the capture date may be related to

651 contaminant exposure in these birds. The contribution of atmospheric exposure to HFR

652 contamination in wildlife is largely unknown. However, it has been confirmed as an important

653 source of exposure to humans via indoor air and house dust (reviewed in: (Hale et al. 2006)), and

654 thus wildlife living in urban areas may be receiving significant (and underestimated) exposure to

655 HFRs via air and associated particles and via ingestion of these contaminated particles during

656 preening. Further research on this avenue of exposure to HFRs in ring-billed gulls is currently

657 ongoing in our laboratory to determine how much this route of exposure may be contributing to

658 their body burdens.

659 Finally, the possibility that exposure to PBDEs may have altered the incubation or nest-

660 site attentiveness of these gulls should be explored as they have been shown to disrupt related

661 endpoints. In laboratory studies, exposure to PBDEs has caused reduced nest-related behavior

662 during courtship and brood rearing in American kestrels (Falco sparverius) (Fernie et al. 2008,

663 Marteinson et al. 2010), as well as reduced nest temperatures during incubation (Sullivan et al.

664 2013). Additionally, in wild male glaucous gulls, greater plasma sum PBDE concentrations were

665 associated with reductions in the hormone prolactin which regulates incubation behavior

666 (Verreault et al., 2008, and references therein). As such to date, exposure to PBDEs appears to 
667 have a negative impact on incubation and prolactin levels in birds, suggesting that this may not

668 explain the positive correlation between PBDEs and time spent at the nest in the present ring-

669 billed gulls, however further research on this avenue may be warranted.

\section{Conclusions}

672 This study demonstrates increased HFR concentrations in ring-billed gull plasma and

673 liver tissues during the incubation period while birds were present at the nesting site. More

674 specifically, bouts of nest-site attendance in ring-billed gulls lasting only a few hours were

675 associated with significant increase in levels of PBDEs and DP isomers (liver and plasma), but

676 not OCs (liver). Conversely, the amount of time that birds were engaged in foraging activities,

677 body condition and percent body fat were unrelated to contaminant concentrations. The changes

678 in plasma HFR concentrations may be consistent with the hypothesis that birds were exposed to

679 a diluted meal with respect to HFR levels, although this would not apply for OCs. However, the

680 patterns in liver do not support this explanation because all hydrophobic organic contaminants

681 should increase in liver as fasting duration increases. Alternatively, these gulls may have been

682 significantly exposed to non-dietary sources of HFRs at the nest site (i.e., via inhalation of air

683 and HFR-laden particles or ingestion via preening of particles adsorbed to their plumage).

684 Ultimately, further study is needed to understand the increased liver and plasma HFR

685 concentrations in these birds while they spend time fasting at the nest site. However, regardless

686 of the underlying mechanisms and exposure routes, the results presented herein highlight the fact

687 that short-term fasting events related to, for example nest-site attendance, may significantly

688 influence levels of HFRs in birds, and hence the potential toxicity associated with these

689 compounds. As such, the amount of time spent in this activity just prior to capture may become 
690 a confounding factor in monitoring and research on contaminants, including biological effect

691 studies in wild birds. This may also apply to a wide variety of other situations where short-term

692 fasting occurs including other reproductive phases, migration, or even daily overnight fasting.

693 Further research on how contaminant concentrations relate to these life cycle stages is warranted.

\section{Acknowledgements}

696 Funding for this study was provided by the Natural Sciences and Engineering Research Council

697 of Canada (NSERC: grant \#385787) (J.V.), the Canada Research Chair in Comparative Avian

698 Toxicology (grant \#225707 J.V.) and Fonds québécois de la recherche sur la nature et les

699 technologies (to S.C.M.). For field assistance the authors thank V. Aponte, S. Pellerin Plourde,

700 M. Patenaude-Monette, M.-L. Gentes, F. St-Pierre, and M. Tremblay. For assistance with stable

701 isotope analysis, the authors thank J.-F. Hélie and A. Adamowicz, and for ArcGIS analysis the

702 authors thank M. Patenaude-Monette and M.-L. Gentes.

703

704 References

705 Alonso-Alvarez C, Ferrer M. 2001. A biochemical study of fasting, subfeeding, and recovery

$706 \quad$ processes in yellow-legged gulls. Physiol Biochem Zool 74:703-713.

707 Beyer A, Biziuk M. 2009. Environmental fate and global distrbution of polychlorinated

708 biphenyls. In: Reviews of Environmental Contamination and Toxicology, Vol.

709 201:Springer, 137-154.

710 Bigsby RM, Caperell Grant A, Madhukar BV. 1997. Xenobiotics released from fat during fasting 711 produce estrogenic effects in ovariectomized mice. Cancer Res 57:865-869. 
712 Birnbaum LS. 1985. The role of structure in the disposition of halogenated aromatic xenobiotics.

713 Environ Health Persp 61:11-20.

714 Braekevelt E, Tittlemier SA, Tomy GT. 2003. Direct measurement of octanol-water partition

715 coefficients of some environmentally relevant brominated diphenyl ether congeners.

$716 \quad$ Chemosphere 51:563-567.

717 Braune BM, Norstrom RJ. 1989. Dynamics of organohclorine compounds in herring gulls: Iii.

718 Tissue distribution and bioaccumulation in lake ontario gulls. Env Toxicol Chem 8:957-

719968.

720 Burnham KP, Anderson DR. 2002. Model selection and multimodel inference - a practical

721 information-theoretic approach. U.S.A.:Springer.

722 Burnham KP, Anderson DR, Huyvaert KP. 2011. AIC model selection and multimodel inference

723 in behavioral ecology: Some background, observations, and comparisons. Behav Ecol

$724 \quad$ Sociobiol 65:23-35.

725 Bustnes JO, Moe B, Herzke D, Hanssen SA, Nordstad T, Sagerup K, et al. 2010. Strongly

726 increasing blood concentrations of lipid-soluble organochlorines in high arctic common

727 eiders during incubation fast. Chemosphere 79:320-325.

728 Caron-Beaudoin E, Gentes ML, Patenaude-Monette M, Hélie J-F, Giroux JF, Verreault J. 2013.

729 Combined usage of stable isotopes and gps-based telemetry to understand the feeding

730 ecology of an omnivorous bird in a heterogeneous landscape. Can J Zool 91:689-697.

731 Cherel Y, Freby F, Gilles J, Robin JP. 1993. Comparative fuel metabolism in gentoo and king

732 penguins - adaptation to brief versus prolonged fasting. Polar Biol 13:263-269. 
Daley JM, Norstrom RJ, Drouillard KG. 2013. Tissue distribution kinetics of 2,2',4,4',5,5'hexachlorobiphenyl in ringdoves after oral dosing. Bull Environ Contam Toxicol 91:367371.

Daley JM, Paterson G, Druillard KG. 2014. Bioamplification as a non-steady state bioaccumulation mechanism for persistent organic pollutants (pops) in wildlife. Rev Environ Contam Toxicol 227:107-155.

Drouillard KG, Norstrom RJ. 2000. Dietary aborption efficiencies and toxicokinetics of polychlorinated biphenyls in ring doves following exposure to arochlor mixtures. Environ Toxicol Chem 19:2707-2714.

Drouillard KG, Norstrom RJ. 2001. Quantifying maternal and dietary sources of 2,2',4,4',5,5'hexachlorobiphenyl deposited in eggs of the ring dove (Streptopelia risoria). Environ Toxicol Chem 20:561-567.

Dulfer WJ, Govers HA. 1995. Solubility and micelle-water partitioning of polychlorinated biphenyls in solutions of bile salt micelles. Chemosphere 30:293-306.

Dulfer WJ, Groten JP, Govers HA. 1996. Effect of fatty acids and the aqueous diffusion barrier on the uptake and transport of polychlorinated biphenyls in caco-2 cells. J Lipid Res $37: 950-961$.

Farley SD, Robbins CT. 1994. Development of 2 methods to estimate body-composition of bears. Can J Zool 72:220-226.

Fernie, KJ, Shutt, JL, Letcher, RJ, Ritchie JI, Sullivan, K, Bird, DM. 2008. Changes in reproductive courtship behaviors of adult American kestrels (Falco sparverius) exposed to environmentally relevent levels of the polybrominated diphenyl ether mixture, DE-71. Toxicol Sci, 102: 171-178. 
Gentes ML, Letcher RJ, Caron-Beaudoin E, Verreault J. 2012. Novel flame retardants in urbanfeeding ring-billed gulls from the St. Lawrence River, Canada. Environ Sci Technol 46:9735-9744.

Gentes ML, Mazerolle MJ, Giroux J-F, Patenaude-Monette M, Verreault J. 2015. Tracking the sources of polybrominated diphenyl ethers in birds: Foraging in waste management facilities results in higher decaBDE exposure in males. Environ Res 138:361-371.

Hale RC, La Guardia MJ, Harvey E, Gaylor MO, Mainor TM. 2006. Brominated flame retardant concentrations and trends in abiotic media. Chemosphere 64:181-186.

Hall AJ, Gulland FMD, Ylitalo GM, Greig DJ, Lowenstine L. 2008. Changes in blubber contaminant concentrations in california sea lions (Zalophus californianus) associated with weight loss and gain during rehabilitation. Environ Sci Technol 42:4181-4187.

Han X, Wang Z, Zhai Z, Wang L. 2006. Estimation of $n$-octanol/water partition coefficients (kow) of all PCB congeners by ab initio and a cl substitution position method. QSAR Combin Sci 25:333-341.

Hebert CE, Keenleyside WJ. 1995. To normalize or not to normalize? Fat is the question. Envion Toxicol Chem 14:801-807.

Helgason LB, Verreault J, Braune BM, Borga K, Primicerio R, Jenssen BM, et al. 2010. Relationship between persistent halogenated organic contaminants and tcdd-toxic equivalents on erod activity and retinoid and thyroid hormone status in northern fulmars. Sci Total Environ 408:6117-6123.

Henriksen EO, Gabrielsen GW, Skaare JU. 1996. Levels and congener pattern of polychlorinated biphenyls in kittiwakes (Rissa tridactyla), in relation to mobilization of body-lipids associated with reproduction. Environ Pollut 92:27-37. 
Horita J, Kendall C. 2004. Stable isotope analysis of water and aqueous solutions by conventional dual-inlet mass spectrometry. In: Handbook of stable isotope analytical techniques, Vol. 1, (De Groot P, ed). New York:Elsevier, 1-37.

Houde M, Berryman D, de Lafontaine Y, Verreault J. 2014. Novel brominated flame retardants and dechloranes in three fish species from the St. Lawrence River, Canada. Sci Total Environ 479-480:48-56.

Jorgensen EH, Bye BE, Jobling M. 1999. Influence of nutritional status on biomarker responses to PCB in the arctic charr (Salvelinus alpinus). Aquat Toxicol 44:233-244.

Keller JM, Kucklick JR, Harms CA, Segars AL, Cluse W, Godfrey M, et al. 2006. Organic contaminant concentrations are higher in debilitated loggerhead turtles compared to apparently healthy ones. 26th Annual Symposium on Sea Turtle Biology and Conservation - Book of Abstracts - International Sea Turtle Society: 63.

Marteinson SC, Fernie KJ, Shutt JL, Letcher RJ, Ritchie JI, Bird DM. 2010. Embryonic exposure to male American kestrels (Falco sparverius) to DE-71 flame retardant via maternal transfer reduces reproductive success and decreases courtship and brood rearing behaviors. Environ Toxicol CHem 29:1740-1747.

Marteinson SC, Giroux J-F, Hélie J-F, Gentes ML, Verreault J. 2015. Field metabolic rate is dependent on time-activity budget in ring-billed gulls (Larus delawarensis) breeding in an anthropogenic environment PLoS1. DOI: 10.1371/journal.pone.0126964

Mata AJ, Caloin M, Robin JP, Le Maho Y. 2006. Reliability in estimates of body composition of birds: Oxygen-18 versus deuterium dilution. Physiol Biochem Zool 79:202-209.

McWilliams SR, Whitman M. 2013. Non-destructive techniques to assess body composition of birds: A review and validation study. J Ornithol 154:597-618. 
Melymuk L, Robson M, Helm PA, Diamond ML. 2012. PCBs, PBDEs, and PAHs in Toronto air: Spatial and seasonal trends and implications for contaminant transport. Sci Total Environ 429:272-280.

Moreno J. 1989. Strategies of mass change in breeding birds. Biol J Linn Soc 37:297-310.

Norstrom RJ, Clark TP, Jeffery DA, Won HT, Gilman AP. 1986. Dynamics of organochlorine compounds in herring gulls: I. Distribution and clearance of [14c]-DDE in free living gulls (Laurus argentatus). Environ Toxicol Chem 5:41-48.

Patenaude-Monette M, Bélisle M, Giroux J-F. 2014. Balancing energy budget in a central-place forager: Which habitat to select in a heterogeneous environment? PLos1. DOI: 10.1371/journal.pone.0102162

Perkins CR, Barclay JS. 1997. Accumulation and mobilization of organochlorine contaminants in wintering greater scaup. $J$ Wildlife Manage 61:444-449.

Polischuk SC, Norstrom RJ, Ramsay MA. 2002. Body burdens and tissue concentrations of organochlorines in polar bears (Ursus maritimus) vary during seasonal fasts. Environ Pollut 118:29-39.

Rodriguez P, Tortosa FS, Villafuerte R. 2005. The effects of fasting and refeeding on biochemical parameters in the red-legged partridge (Alectoris rufa). Comp Biochem Phys A 140:157-164.

Routti H, Helgason LB, Arukwe A, Wolkers H, Heimstad ES, Harju M, et al. 2013. Effect of reduced food intake on toxicokinetics of halogenated organic contaminants in herring gull (Larus argentatus) chicks. Environ Toxicol Chem 32:156-164.

Ryder JP. 2012. Ring-billed gull. In: Birds of North America, Part 2012:Cornell Lab of Ornithology. 
825 Scollon EJ, Carr JA, Rintoul DA, McMurry ST, Cobb GP. 2012. Metabolism and distribution of $826 p, p^{\prime}$-DDT during flight of the white-crowned sparrow, Zonotrichia leucophrys. Environ 827 Toxicol Chem 31:336-346.

828 Shaffer SA, Gabrielsen GW, Verreault J, Costa DP. 2006. Validation of water flux and body composition in glaucous gulls (Larus hyperboreus). Physiol Biochem Zool 79:836-845.

830 Shoeib M, Ahrens L, Jantunen L, Harner T. 2015. Concentrations in air of organobromine and organophosphate flame retardants in Toronto Canada. Atmos Environ 99:140-147.

832 Sullivan KM, Marteinson SC, Letcher, RJ, Bird DM, Ritchie IJ, Shutt, JL, Fernie KJ. 2013.

833 Changes in the incubation by American kestrels (Falco sparverius) during exposure to the polybrominated diphenyl ether (PBDE) mixture DE-71. J Toxicol Environ Health A 76:

Totzke U, Fenske M, Huppop O, Raabe H, Schach N. 1999. The influence of fasting on blood and plasma composition of herring gulls (Larus argentatus). Physiol Biochem Zool 72:426-

van den Brink NW, van Franeker JA, Ruiter-Dijkman EM. 1998. Fluctuating concentrations of organochlorine pollutants during a breeding season in two antarctic seabirds: Adélie

842 Vanden Berghe M, Weijs L, Habran S, Das K, Bugli C, Rees JF, et al. 2012. Selective transfer of persistent organic pollutants and their metabolites in grey seals during lactation. Environ

845 Veith GD, DeFoe DL, Bergstedt BV. 1979. Measuring and estimating the bioconcentration factor of chemicals in fish. Journal of the Fisheries Research Board of Canada 36:10401048. 
848 Venier M, Hites RA. 2008. Flame retardants in the atmosphere near the Great Lakes. Environ Sci $849 \quad$ Technol 42:4745-4751.

850 Verreault J, Shahmiri S, Gabrielsen GW, Letcher RJ. 2007. Organohalogen and metabolically851 derived contaminants and associations with whole body constituents in Norwegian Arctic 852 glaucous gulls. Environ Int 33:823-830.

853 Verreault J, Verboven N, Gabrielsen GW, Letcher RJ, Chastel O. 2008. Changes in prolactin in a 854 highly organohalogen contaminated Arctic top predator seabird, the glaucoud gull. Gen $855 \quad$ Comp Endocrinol 156:569-576.

856 Vijayan MM, Aluru N, Maule AG, Jorgensen EH. 2006. Fasting augments PCB impact on liver 857 metabolism in anadromous arctic char. Toxicol Sci 91:431-439.

858 Wang T, Hung CCY, Randall DJ. 2006. The comparative physiology of food deprivation: From 859 feast to famine. An Rev Physiol 68:223-251.

860 Wingfield JC. 1994. Modulation of the adrenocortical response to stress in birds. In: Perspectives 861 in comparative endocrinology, (Davey KG, Peter RE, eds). Ottawa, Canada:National 862 Research Council of Canada, 520-528. 


\begin{tabular}{|c|c|c|c|c|c|}
\hline $\begin{array}{l}\text { Response } \\
\text { variable }\end{array}$ & Model & $\begin{array}{c}\text { Parameter estimate } \\
\text { B (CI) }\end{array}$ & $\Delta \mathrm{AIC}_{\mathrm{c}}$ & $w$ & $R^{2}$ \\
\hline $\begin{array}{c}\Sigma_{37} \mathrm{PBDEs} \\
\text { liver } \\
(n=25)\end{array}$ & $\begin{array}{l}\text { \# hours at nest-site }+ \text { capture date } \\
\% \text { nest-site attendance }+ \text { capture date } \\
\text { plasma lipid } \%+\text { date } \\
\text { plasma lipid } \%+\% \text { nest-site attendance } \\
\text { capture date } \\
\% \text { nest-site attendance } \\
\text { \# hours at nest-site } \\
\% \text { plasma lipids } \\
\text { sex } \\
\text { null }\end{array}$ & $\begin{array}{r}1.0(0.3-1.7) ;-8.8(-14--2.7) \\
499.5(33.0-966.0) ;-7.5(-14.3--0.7) \\
-7.7(-14.5--0.9) ;-200.4(-395.5--5.3) \\
-201.3(-397.9--4.64) 513.5(42.3-984.8) \\
-10.1(-17.0--3.2) \\
682.4(237.8-1158.1) \\
1.2(0.4-2.0) \\
-2.8(-476.6--76.0) \\
-147.3(-270.0--24.5) \\
\mathrm{n} / \mathrm{a}\end{array}$ & $\begin{array}{l}0 \\
2.49 \\
2.79 \\
3.07 \\
3.69 \\
3.95 \\
3.96 \\
4.41 \\
5.82 \\
8.22 \\
\end{array}$ & $\begin{array}{l}0.43 \\
0.12 \\
0.11 \\
0.09 \\
0.07 \\
0.06 \\
0.06 \\
0.05 \\
0.02 \\
0.01\end{array}$ & $\begin{array}{l}0.38 \\
0.36 \\
0.35 \\
0.35 \\
0.25 \\
0.24 \\
0.24 \\
0.23 \\
0.18 \\
\mathrm{n} / \mathrm{a}\end{array}$ \\
\hline $\begin{array}{c}\Sigma_{37} \mathrm{PBDEs} \\
\text { plasma } \\
(n=29)\end{array}$ & $\begin{array}{l}\% \text { nest-site attendance } \\
\text { \# hours at nest-site }+ \text { date } \\
\text { sex } \\
\text { date } \\
\text { \# h nest-site } \\
\text { null }\end{array}$ & $\begin{array}{r}117.0(21.7-212.2) \\
0.1(0.0-0.3) ;-1.5(-2.8--0.1) \\
-24.5(-47.6--1.4) \\
-1.5(-3.0--0.4) \\
0.2(0.0--0.1) \\
\mathrm{n} / \mathrm{a} \\
\end{array}$ & $\begin{array}{c}0 \\
0.51 \\
1.24 \\
1.48 \\
1.7 \\
2.70 \\
\end{array}$ & $\begin{array}{l}0.29 \\
0.22 \\
0.15 \\
0.14 \\
0.12 \\
0.07 \\
\end{array}$ & $\begin{array}{r}0.18 \\
0.24 \\
0.14 \\
0.13 \\
0.12 \\
\text { n/a }\end{array}$ \\
\hline
\end{tabular}

$\mathrm{B}=$ parameter estimates. $\mathrm{CI}=95 \%$ confidence intervals. $\Delta \mathrm{AIC}_{\mathrm{c}}=$ the difference in Akaikes Information Criterion (corrected for

868 small sample sizes value) between a model and the top model. $w=$ model weight. The $R^{2}$ refers to the adjusted coefficient of

869 determination generated from linear regression analysis. Variables with AICc values above the null model (thus explaining no

870 variation in the response variable) included body mass, condition index, Julian lay date, proportion of time spent foraging, proportion 
871 of time spent in different habitat types (urban, agricultural, waterway), percent body water or fat and for plasma $\Sigma_{37} \mathrm{PBDEs}$ the $\%$ 872 plasma lipids.

873

874 
875 Figure 1: Mean concentrations $( \pm$ SEM) of organochlorines and halogenated flame retardants in

876 liver of ring-billed gulls (Larus delawarensis) collected during the incubation period near

877 Montreal (QC, Canada).

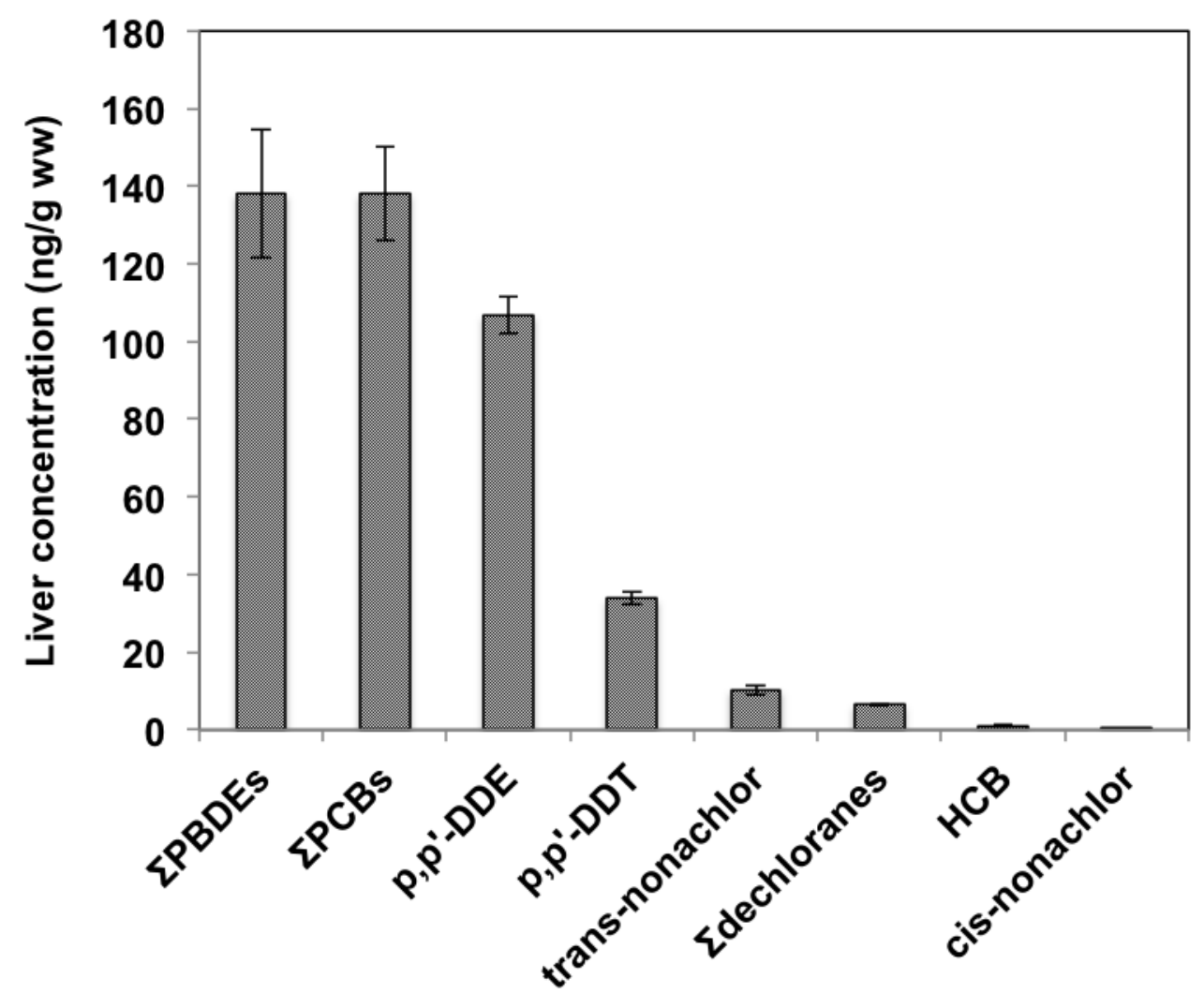

879 
880 Figure 2: Relationship (Spearman's Rank Correlation) between plasma lipid percent and 881 number of hours spent at the nest site in the last 24 hours prior to recapture in incubating ring882 billed gulls (Larus delawarensis) near Montreal (QC, Canada). Birds with less than 1\% plasma 883 lipids (dashed line) were assumed to be in a fasted state (K. Drouillard, unpublished data).

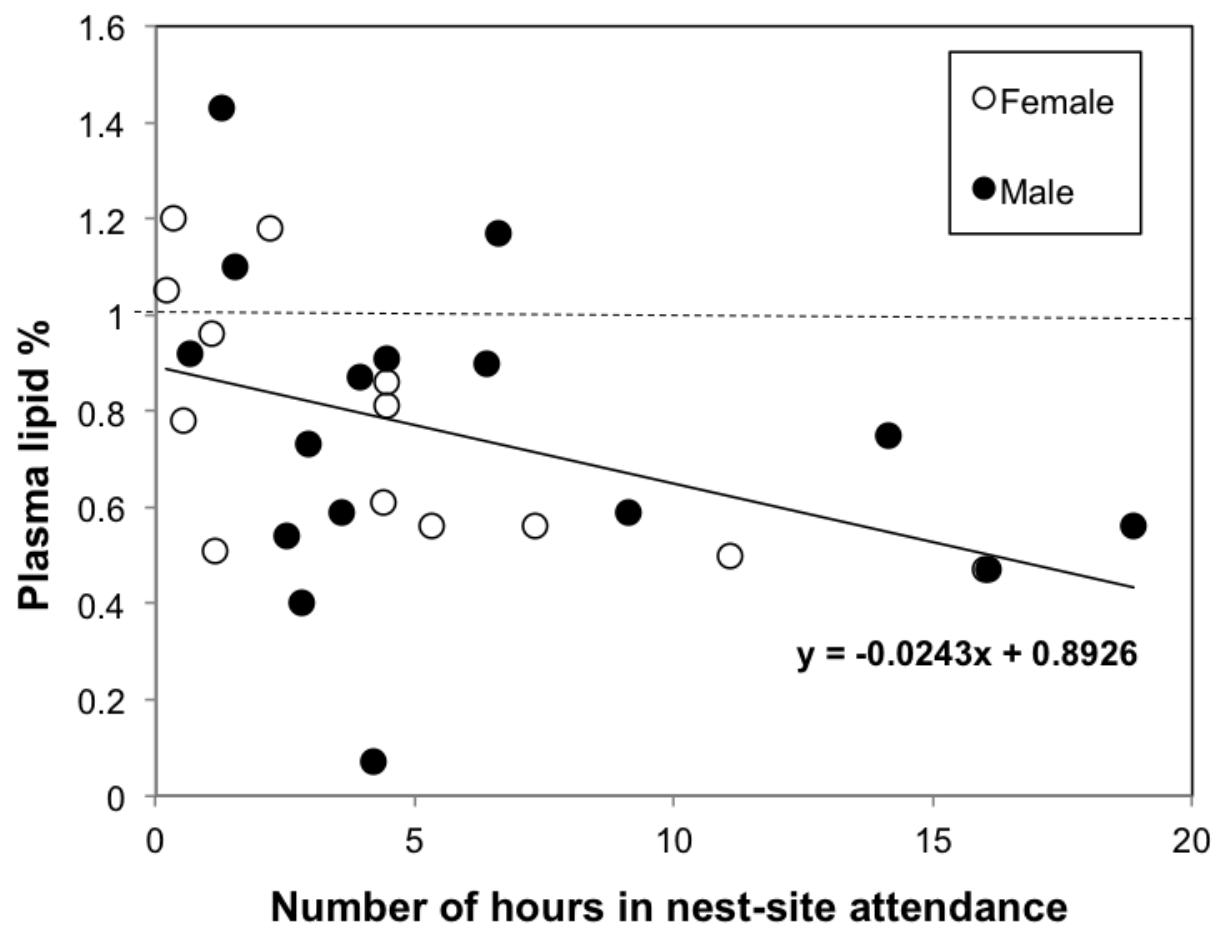

884 
886 Figure 3: Relationships (Spearman's Rank Correlation) between the concentrations of $\Sigma_{37} \mathrm{PBDE}$ 887 in liver (A) and plasma (B) and (C) $\Sigma_{38}$ PCBs in liver and the percent lipids determined in plasma 888 of incubating ring-billed gulls (Larus delawarensis) near Montreal (QC, Canada).
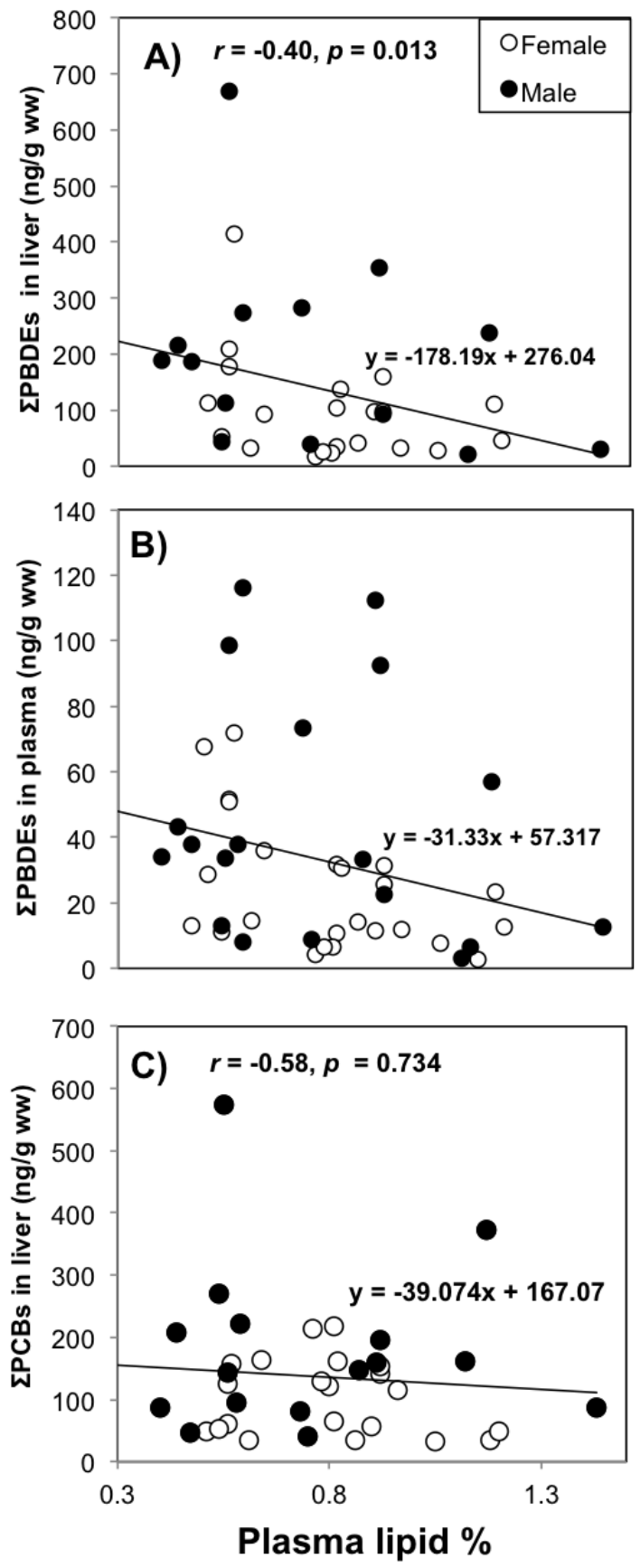
890 Figure 4: Relationships (Spearman's Rank Correlation) between the number of hours birds spent 891 attending the nest-site in the last 24 hours prior to recapture and $\Sigma_{37} \mathrm{PBDE}$ concentrations in A)

892 plasma and B) liver, and C) $\Sigma_{38} \mathrm{PCBs}$ in liver of incubating ring-billed gulls (Larus delawarensis)

893 near Montreal (QC, Canada).
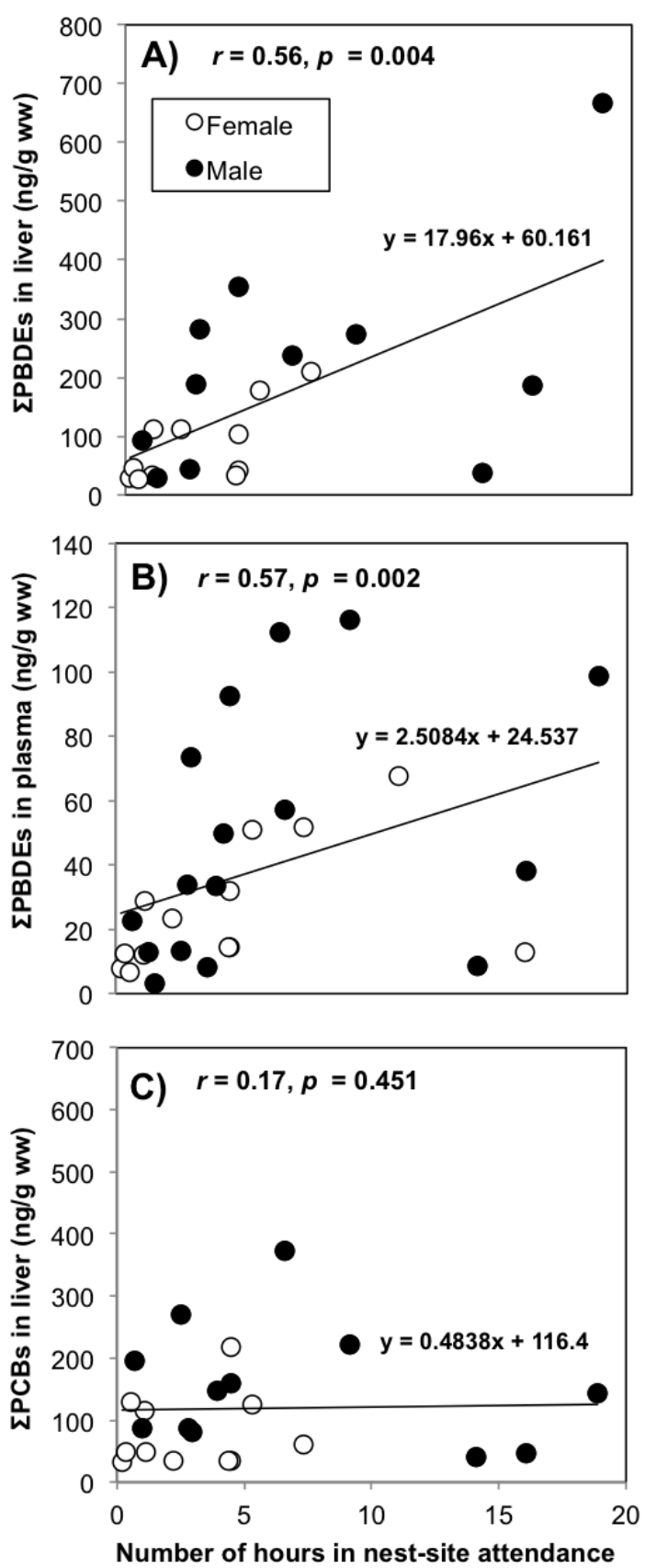

894 


\section{Supplementary information}

896

897 Methods

898 Figure S1: Relationship between total body water and total body fat of glaucous Gulls (Larus

899 hyperboreus) from Svalbard, Norway. Data from Shaffer et al. (2006) and Verreault et al.

900 (2007).

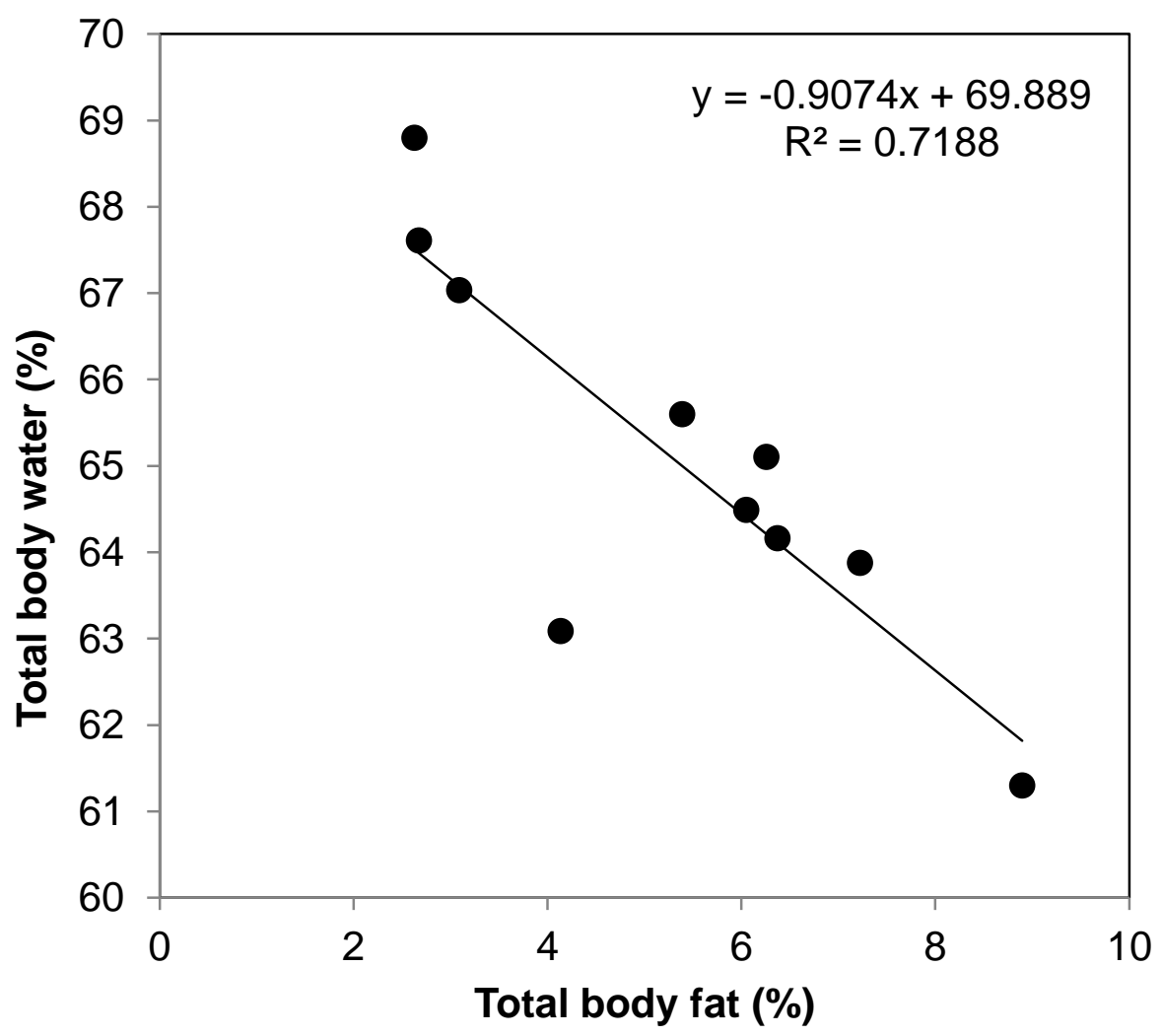

901

902

903

904 


\section{$906 \underline{\text { Results }}$}

907 Figure S2: Concentrations of major PBDE congeners determined in liver and plasma of ring-

908 billed gulls (Larus delawarensis) during the incubation phase near Montreal (QC, Canada).

909

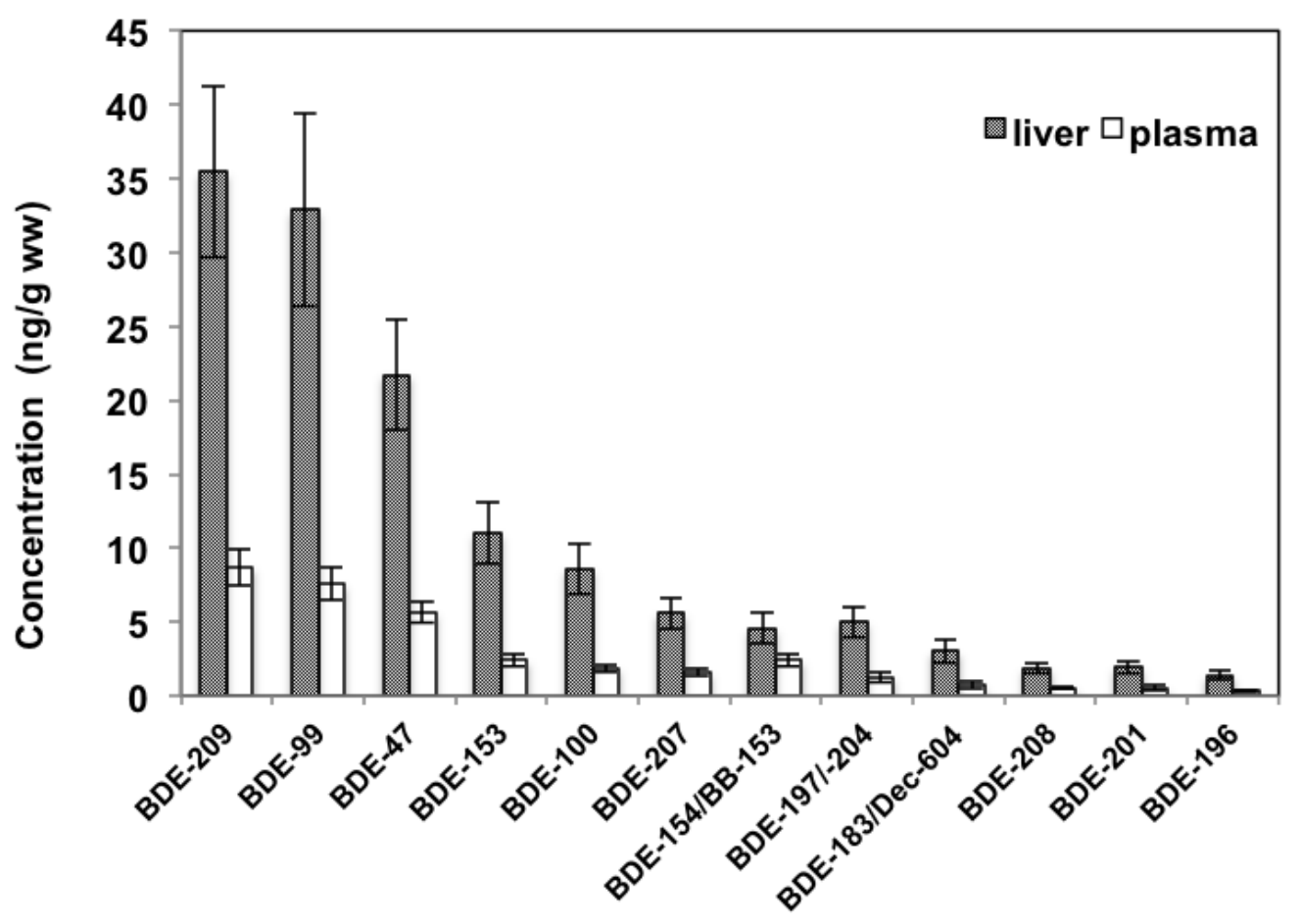

910

911

912 
913 Figure S3: Concentrations of major PCB congeners determined in liver of ring-billed gulls

914 (Larus delawarensis) during the incubation phase near Montreal (QC, Canada).

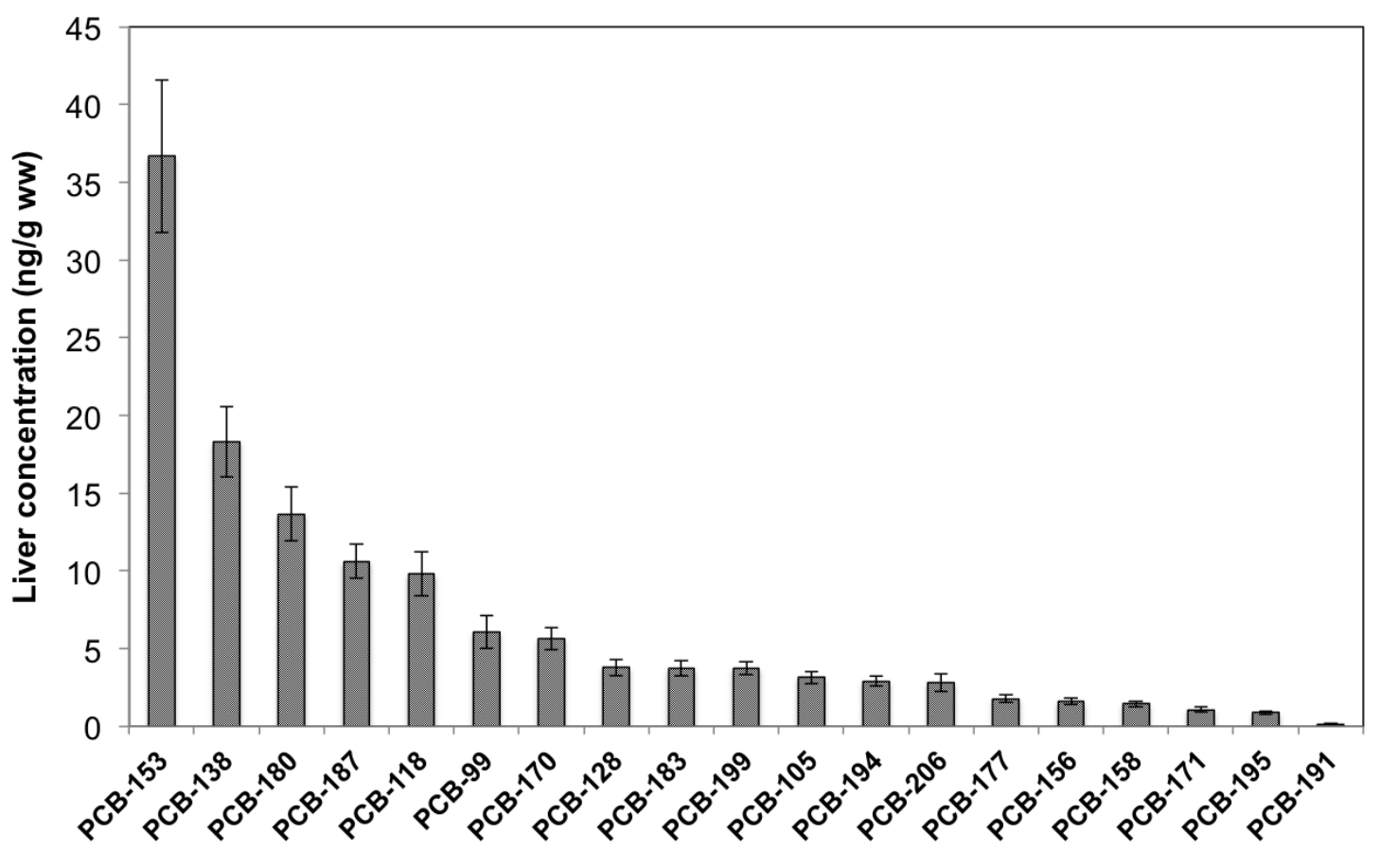

916

917 
918 Figure S4: Concentrations of $\Sigma_{37} \mathrm{PBDE}$ vs. $\Sigma_{38} \mathrm{PCBs}$ in liver of ring-billed gulls (Larus

919 delawarensis) nesting near Montreal (QC, Canada). Points above the dashed line represent birds

920 for which $\Sigma$ PBDE exceed $\Sigma$ PCB concentrations and vice versa for points below this line.

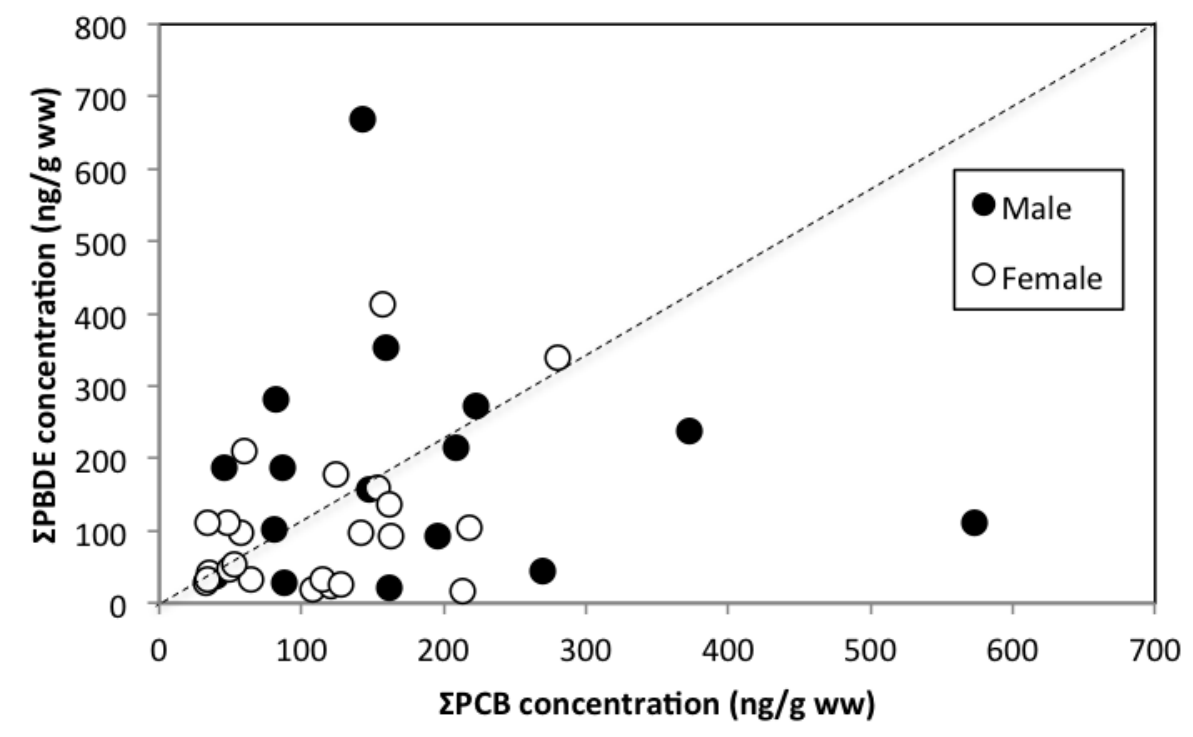


924 Relationships between lipid-corrected plasma HFR concentrations and time-activity budget

925 As the proportion of time that birds spent in nest-site attendance increased, so did their

926 lipid-corrected concentrations of $\Sigma_{37} \mathrm{PBDEs}$ plasma $(r=0.46, p=0.012)$ as well as several of the

927 individual PBDE congeners (in order of decreasing $r$ : BDE-154/BB-153, -47, -99, -100, -153, -

$928201,-197,-183: 0.39<r<0.43,0.007<p<0.003)$. The positive relationship between nest-site

929 attendance and PBDEs was stronger when the number of hours at the nest site before recapture

930 was considered; all lipid-corrected congener concentrations were positively related to this

931 activity measure $(0.046>p>0.001)$ as were $\Sigma_{37} \operatorname{PBDEs}(r=0.61, p=0.001$; Fig. S5 $)$ and

$932 \Sigma$ dechloranes $(r=0.39, p=0.043)$.

933

934 Figure S5: Relationship (Spearman's Rank Correlation) between the number of hours birds were 935 attending the nest-site in the last 24 hours prior to recapture and lipid corrected $\Sigma_{37} \mathrm{PBDE}$

936 concentrations in plasma of incubating ring-billed gulls (Larus delawarensis) near Montreal

937 (QC, Canada).

938

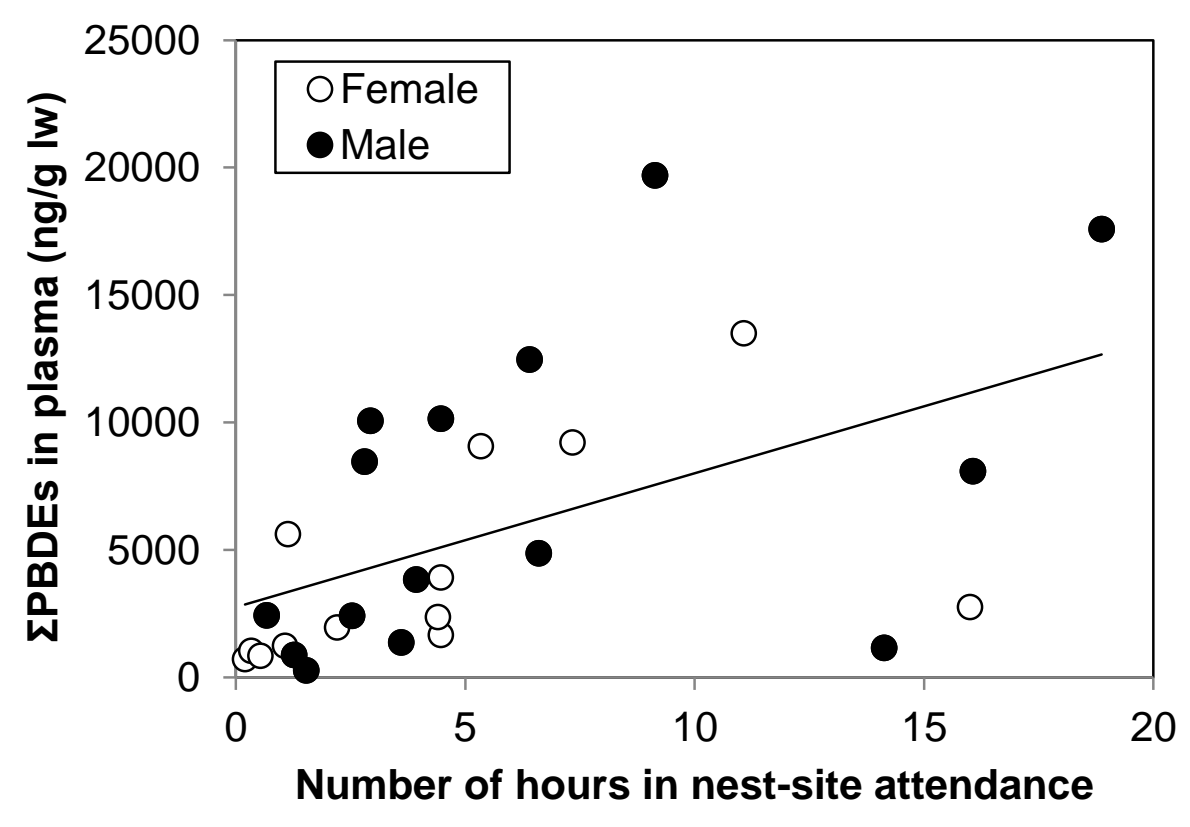

